\title{
Nucleosome positioning on the MMTV LTR results from the frequency-biased occupancy of multiple frames
}

\author{
Gilberto Fragoso, Sam John, ${ }^{1}$ M. Scot Roberts, and Gordon L. Hager ${ }^{2}$ \\ Laboratory of Molecular Virology, National Cancer Institute, National Institutes of Health, Bethesda, \\ Maryland 20892-5055 USA
}

\begin{abstract}
The translational positions of nucleosomes in the promoter region of the mouse mammary tumor virus (MMTV) were defined at high resolution. Nucleosome boundaries were determined in primer extension assays using full-length single-stranded mononucleosomal DNA prepared from cells treated with formaldehyde, a reversible protein-DNA cross-linking agent. Multiple boundaries were observed in both the nucleosome A (Nuc-A) and Nuc-B region of the promoter, indicating multiple nucleosome translational frames. The different nucleosome frames in both the Nuc-A and Nuc-B regions were occupied unequally. The most frequently occupied frames were found clustered within 50-60 bases of each other, resulting in a distribution centered in the positions defined previously at low resolution for Nuc-A and Nuc-B. The most abundant $5^{\prime}$ ends of the frames in the $B$ region were found between -235 and -187 , and the $3^{\prime}$ ends between -86 and -36 , whereas in the $A$ region the most abundant $5^{\prime}$ ends were between -22 and +42 , and the $3^{\prime}$ ends between +121 and +186. Although frames in the Nuc-B region of the LTR extend at a low frequency in the $5^{\prime}$ direction toward the Nuc- $C$ region, there is a sharp discontinuity in the $3^{\prime}$ direction toward Nuc-A, suggesting the presence of a boundary constraint in the A-B linker. The positions and relative occupancies of nucleosome frames, in either the $B$ or the A region, did not change when the promoter was activated with dexamethasone.
\end{abstract}

[Key Words: MMTV LTR; nucleosome positioning; phasing; frequency-biased occupancy; translational frames; histone octamer]

Received March 30, 1995; revised version accepted June 15, 1995.

The mouse mammary tumor virus (MMTV) promoter adopts a highly reproducible chromatin organization when introduced into mammalian cells. A periodic micrococcal nuclease (MNase) and methidiumpropylEDTA-iron [MPE-Fe(II)] digestion pattern consistent with six positioned nucleosomes (designated A-F) has been observed for the long terminal repeat (LTR) in a variety of contexts (Richard-Foy and Hager 1987). Chromatin in the promoter region, nucleosomes A (Nuc-A) and $B(N u c-B)$, has been characterized further at high resolution (Bresnick et al. 1992b; Truss et al. 1993; Mymryk et al. 1995); at base-pair resolution, the nucleoprotein structure in different cells is again found to be indistinguishable, even with the promoter fused to a variety of reporter genes, and the constructs present in different copy numbers.

Steroid receptors bind to the MMTV LTR at Nuc-B and induce a chromatin transition detected as hypersensitivity to DNase I, MPE-Fe(II), or restriction endonucleases

\footnotetext{
'This work was submitted in partial fulfillment of the Ph.D. requirements for the Genetics Department at George Washington University, Washington, D.C.

${ }^{2}$ Corresponding author.
}

(Zaret and Yamamoto 1984; Peterson 1985; Richard-Foy and Hager 1987; Archer et al. 1991). In vivo exonuclease footprinting reveals the presence of a multifactor complex on the hormonally stimulated promoter; this complex includes members of the basal initiation complex (TFIID), and immediate proximal activators (NF-I/CTF, OTF-1) (Cordingley et al. 1987; Archer et al. 1992; Pennie et al. 1995). One of these factors, NF-I, does not bind reconstituted B nucleosomes in vitro, although the glucocorticoid receptor will (Perlmann and Wrange 1988; Pina et al. 1990b; Archer et al. 1991). This differential binding ability suggests that the chromatin transition is required for, and mechanistically important to, promoter activation (Archer et al. 1992). Therefore, it is critically important to characterize the nucleosomal organization of the promoter to understand the nature of the steroid hormone-induced transition.

The structural basis for the highly reproducible MMTV chromatin structure is not understood currently. Short fragments of the LTR, when reconstituted with histones into nucleosomes in vitro, will wrap on the histone octamer with the DNA in a rotationally fixed orientation (Perlmann and Wrange 1988; Pina et al. 1990a,b; Bresnick et al. 1991), leading to the suggestion 
that cores on the MMTV LTR, the B nucleosome in particular, may adopt a unique rotational and translational position (Truss et al. 1992). Although our previous characterization of A-B region chromatin indicated a highly reproducible structure (Richard-Foy and Hager 1987; Bresnick et al. 1992b), we have been unable to obtain evidence for unique rotational and translational positioning.

Several problems must be overcome in efforts to map the path of DNA on nucleosomes in vivo. Reagents, such as DNase I, often used to reveal nonrandom wrapping of DNA do not cleave DNA in a sequence independent fashion; therefore, chromatin-specific patterns must be related to protein-free-DNA cutting profiles (Drew and Calladine 1987). Although micrococcal nuclease manifests a strong bias for linker DNA, mononucleosome preparations generated with this reagent contain significant levels of DNA cleavage internal to the core, compromising the subsequent assignment of core boundaries obtained from primer extension assays using DNA isolated from nucleosome core particles (Bresnick et al. 1992b|. Finally, movement of histone octamers along the DNA during the isolation of chromatin and core particles is also a serious problem, migration of core histones has been clearly documented (Pennings et al. 1991; Meersseman et al. 1992).

We have developed an approach to core mapping that addresses the most serious difficulties, that of internal core cleavage and potential core movement. First, we have introduced a formaldehyde cross-linking step to fix nucleosomes in their in vivo positions before cell breakage (Jackson 1978; Jackson and Chalkley 1981; Solomon and Varshavsky 1985). Second, we isolate core-length single-stranded mononucleosomal DNA from the fixed material (Buttinelli et al. 1993); the nucleosome-length DNA is then used as a template for primer extension reactions as described previously (Bresnick et al. 1992b). This last step ensures that the products obtained in the primer extension reactions are attributable to MNase cuts at, or in the immediate vicinity of, core boundaries, and not attributable to cleavage events generated by MNase within cores.

Using this approach, we have discovered that nucleosomes on the Nuc-B and Nuc-A regions of the MMTV LTR are present in the population in a series of overlapping frames. The frame occupancy is biased such that the more frequently occupied frames are clustered, in a manner reminiscent of statistical positioning (Kornberg and Stryer 1988). This frequency-biased occupancy of frames accounts for the nucleosome positioning observed on the MMTV LTR at low resolution in indirect end-labeling experiments (Richard-Foy and Hager 1987). We also find that the frequency of nucleosome site occupancy is very similar in two cell lines characterized in detail; thus, although the nucleoprotein structure acquired by the LTR is more complex than previously suspected, the organization is highly reproducible and clearly directed by features of DNA sequence or DNA-binding proteins, or both. Finally, the cross-linking assay does not detect a significant difference in either the nucleosome positions, or the frame occupancy, in the Nuc-A or Nuc-B regions of untreated and steroid hormone-treated cells.

\section{Results}

\section{Cell lines and experimental scheme}

The 904.13 and 1471.1 cell lines contain MMTV LTRreporter constructs mobilized on bovine papillomavirus (BPV)-episomes in a $\mathrm{C} 127$ mouse mammary cell background (see Materials and methods). The high copy number of the constructs in these cells facilitates the analysis of their chromatin structure as linear amplification primer extension methodologies can be used to examine the nuclease cleavage patterns. The LTR drives the chloramphenicol acetyltransferase (CAT) gene in the 1471.1 cells, and $v-H a$-ras in the 904.13 cells. The MMTV promoter in both cell lines responds to dexamethasone stimulation with the same kinetics as judged by the nuclease sensitivity of the promoter; maximal activation is observed at $1 \mathrm{hr}$ of treatment (Archer et al. 1994; G. Fragoso, W. Pennie, S. John, and G.L. Hager, unpubl.). In indirect end-labeling experiments the MNase digestion pattern of the LTR in 1471.1 cells is the same as in the 1361.5 cell line (data not shown) in which, along with the 904.13 cell line, positioning of nucleosomes in the MMTV LTR was first observed (Richard-Foy and Hager 1987). In addition, with the exception of one site in the Nuc-A region, both cell lines exhibit the same pattern of restriction enzyme access through the LTR as MMTV provirus (G. Fragoso, W. Pennie, S. John, and G. Hager, unpubl.). These two cell lines were chosen for analysis, not only to ensure reproducibility in the nucleosome boundary determinations, but to determine at high resolution whether nucleosome positioning in the promoter region of MMTV is affected by the flanking reporter sequences.

The scheme for the preparation and analysis of nucleosomal DNA is shown in Figure 1. Nuclei are prepared from formaldehyde-fixed cells and digested with MNase. After protease treatment and reversal of the residual protein-DNA cross-links, the nuclease digest is resolved electrophoretically and the mononucleosomal DNA isolated. The double-stranded nucleosomal DNA is then electrophoresed in a denaturing gel to purify the fulllength single-stranded DNA. This DNA is used as a template in primer extension assays; the extension products define the ends, or boundaries, of core histone-associated DNA. A similar approach was used previously in our laboratory to determine the positions of Nuc-A and Nuc-B (Bresnick et al. 1992b); however, among the extension products observed were bands that possibly originated from nicked DNA generated by MNase during the preparation of core particles. Alternatively, these bands could have arisen from new positions adopted by the histone octamer if the histones slid on the DNA at some point during the isolation of core particles. Sliding has been shown to occur in vitro in low salt conditions (Pennings et al. 1991; Meersseman et al. 1992).

Two additional steps were included in the preparation 


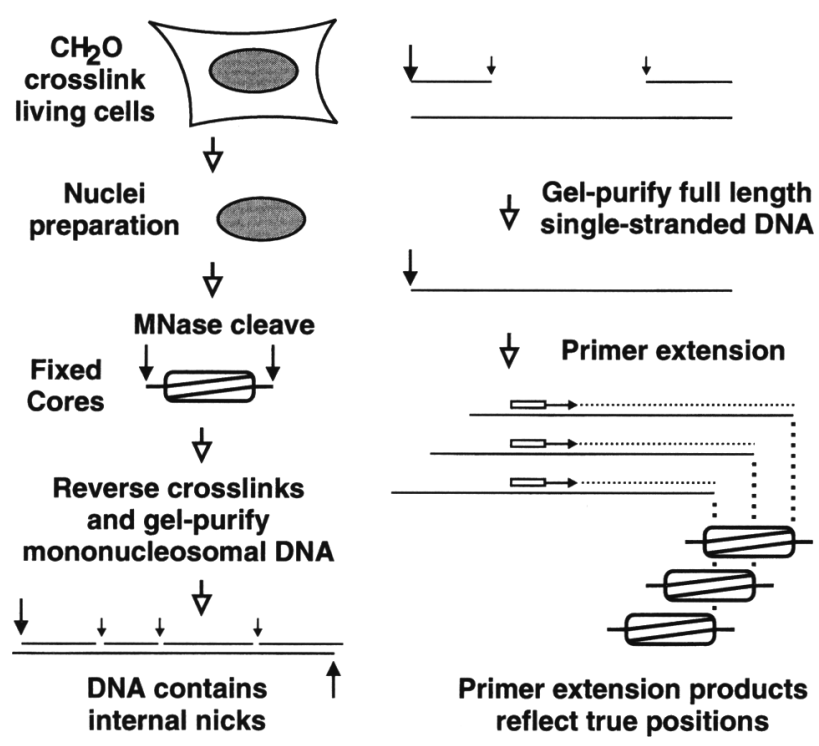

Figure 1. Scheme for the preparation and analysis, by primer extension, of full-length, single-stranded mononucleosomal DNA from formaldehyde-fixed cells.

of the nucleosomal DNA to eliminate the potential sources of artifact mentioned above. First, formaldehydefixed cells were used for the preparation of nuclei. We chose formaldehyde as a cross-linking agent to fix histones to DNA in their in vivo positions for several reasons. The characteristic MNase and DNase I digestion pattern of native chromatin is preserved after cross-linking (Jackson and Chalkley 1981), soluble core histones pretreated with formaldehyde do not react with free DNA (Jackson and Chalkley 1981), and the cross-links are thermally reversible (Jackson 1978; Solomon and Varshavsky 1985|. The last point is important because it allows the DNA preparation to be used as a template in primer extension assays. This was confirmed in primer extension reactions using restriction enzyme-treated genomic DNA obtained from fixed cells; the presence of single primer extension products demonstrated that the thermal reversal was complete (data not shown). The second step that we included involved the isolation of full-length single-stranded nucleosomal DNA. This eliminated the uncertainty that primer extension products might result from nicks within the nucleosomal DNA. This step was also used in the analysis of in vivo nucleosome positions of the yeast 5S rRNA gene and in ARS1 chromatin (Buttinelli et al. 1993; Venditti et al. 1994).

\section{Preparation of single-stranded nucleosomal DNA}

An analysis of the single-stranded nucleosomal DNA at different stages of the preparation procedure is shown in Figure 2. MNase digestions conducted with the aim of preparing mononucleosomal DNA from nuclei prepared from fixed cells required a compromise in terms of the extent of digestion that could be reached. The time course of digestion in Figure 2A shows that subnucleosomal-sized DNA (open arrows) starts accumulating long before the chromatin is completely digested to core size (closed arrow), with detectable levels even at $10 \mathrm{~min}$ of digestion (lane 1). Large-scale digests were performed as in lane 1 of Figure $2 \mathrm{~A}$ and the isolated DNA was electrophoresed through preparative gels to band-purify the mononucleosomal DNA. The appearance of the

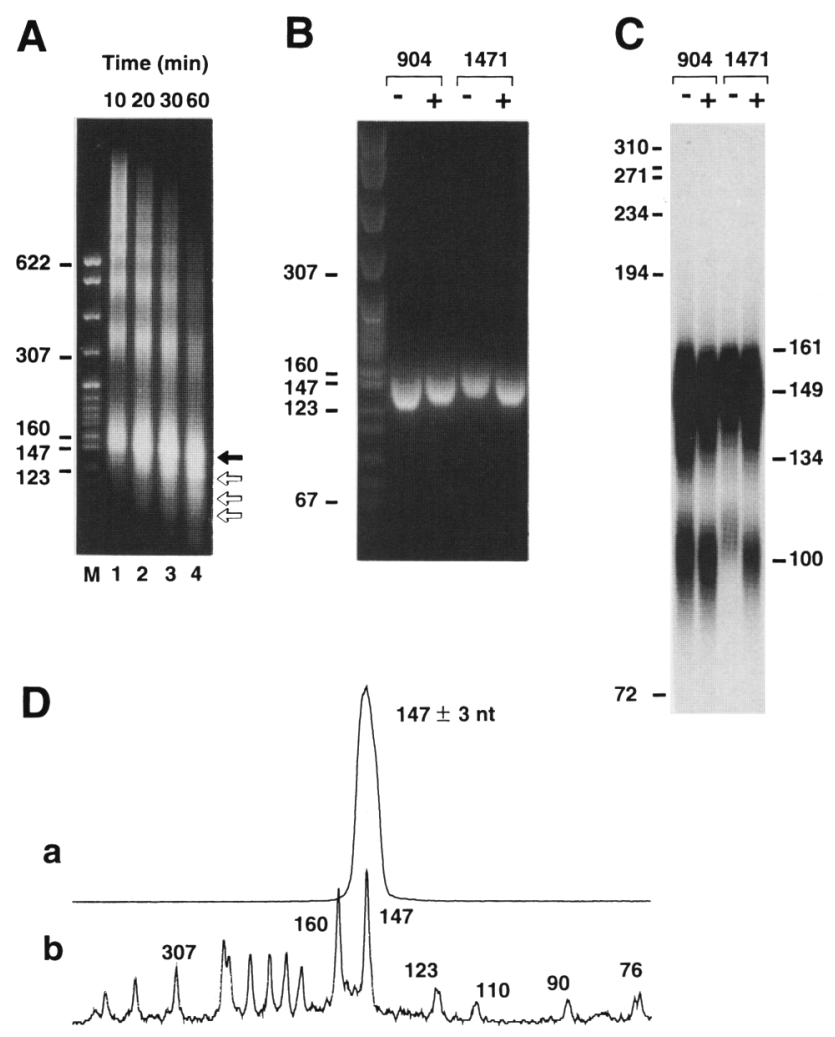

Figure 2. Preparation of mononucleosomal DNA from untreated and dexamethasone-treated 904.13 and 1471.1 cells. $(A)$ Time course of digestion with MNase. (Top) Times of digestion; (left) size in base pairs of selected DNA marker bands; (solid arrow) core-sized DNA; (open arrows) subnucleosomal-sized DNA fragments. Electrophoresis in $2.5 \%$ agarose (NuSieve) gel in TBE. (B) Analysis of the recovered double-stranded mononucleosomal DNA. (Top) Cells and treatments; (left) sizes in base pairs of selected DNA marker bands in the left lane. Electrophoresis of native samples as in $A$. The gel was overloaded to demonstrate the absence of low molecular weight DNA. $(C)$ Analysis of nicks in the mononucleosomal DNA samples shown in $B$. Samples were end-labeled, denatured, and electrophoresed in an $8 \%$ acrylamide/ $8.3 \mathrm{M}$ urea gel in TBE. (Left) Sizes of end-labeled markers; (right) estimated sizes. $(D)$ Size distribution of gel-purified single-stranded nucleosomal DNA. After isolation of nucleosomal DNA from the 147-nucleotide region of preparative gels run under denaturing conditions /see Materials and methods), samples were analyzed in sequencing gels. (a) Scan of the DNA obtained from the control 904.13 cells; $(b)$ scan of the end-labeled DNA marker, size (in nucleotides) of selected bands. The full-length mononucleosomal DNA used for the primer extension assays displayed a size distribution of $147 \pm 3$ nucleotides (1 S.D.). 
mononucleosomal DNA isolated from the untreated and the 1-hr dexamethasone-treated 904.13 and 1471.1 cells is shown in Figure 2B (native double-stranded DNA) and $2 \mathrm{C}$ (end-labeled and electrophoresed in a sequencing gel). Figure $2 \mathrm{C}$ demonstrates that between $5 \%$ and $15 \%$ of the double-stranded DNA in the different samples contained nicks. Preparative denaturing gels were run as in Figure $2 \mathrm{C}$ and the recovered material exhibited the size distribution shown in Figure 2D (scan a), $70 \%$ of the DNA was $147 \pm 3$ bases long, and $95 \%$ was $147 \pm 8$ bases (size markers are shown in scan b).

\section{Assignment of nucleosomal boundaries}

The products of primer extension obtained with nucleosomal DNA templates reflect the boundaries of nucleosomal cores. The assignment of boundaries was straightforward in cases where single or doublet bands were observed to be well spaced from neighboring bands in the sequencing gels. The assignment denoted the position at which the MNase cuts the DNA sequence. [The positions that we report for the MNase cuts differ from those reported previously (Bresnick et al. 1992b), although the cuts we observe occur at the same places. The reasons for the different numbers reported here are (1) we have taken into account for the extra nucleotide added by Taq polymerase to the $3^{\prime}$ end of an elongated chain (Clark 1988), and (2) we have chosen to report the position of the primer-proximal band in a cluster of bands instead of the position of the most intense band.] Likewise, in cases where cuts were observed at consecutive positions in a short run of residues, the small cluster of bands /three to five) was assigned collectively to one boundary, with the band proximal to the primer denoting either its $5^{\prime}$ or $3^{\prime}$ end. Such clusters of bands were presumed to arise from the exonucleolytic activity of the MNase acting on a specific DNA molecule after the initial double-stranded cut (Noll and Kornberg 1977). For the cases where the MNase cuts a longer run of residues, the sequence specificity of MNase action (Dingwall et al. 1981; Horz and Altenburger 1981) was taken into account to determine whether two closely spaced short clusters were to be assigned to one or two boundaries. The two clusters would be taken to represent distinct boundaries if the DNA sequence between the two clusters was deemed suitable for cutting by MNase. The action of MNase on some of the sequences between band clusters was tested directly on naked DNA (data not shown). Otherwise, the cluster of bands would be assigned to a single boundary unless there was unambiguous evidence from primer extension reactions in the opposite direction indicating two nucleosome frames in that region.

MNase cuts in the $5^{\prime}$ direction were matched to cuts in the $3^{\prime}$ direction separated by $\sim 146 \mathrm{bp}$. To ascertain consistency in the matches, the cumulative intensity of sets of bands assigned to one boundary relative to the neighboring boundaries in one end was compared to the matched set of boundaries in the opposite end. No further constraints were imposed. Once these two steps were taken, matching boundaries to frames was self ev- ident; the matched $5^{\prime}$ and $3^{\prime}$ boundaries define frames that we have denoted according to the nucleosome region they are located in, A or B, followed by an identifying number. Increasing odd or even numbers were used for upstream and downstream frames, respectively.

\section{Determination of the Nuc-B boundaries using single-stranded nucleosomal DNA}

Primer extension reactions conducted with the fulllength single-stranded templates, and using oligonucleotides designed to detect the $5^{\prime}$ boundaries of Nuc-B, are shown in Figure 3A. Priming to the $5^{\prime}$ end of Nuc-B with oligonucleotide 749 (Fig. 3A, lanes 1-4; see Fig. 3B for location of primer) resulted in strong bands at positions -235 (denoted as frame B5), -226 (B3), and -215 (B1), and a number of lighter bands at downstream positions (B2 at -205 , B4 at -193 , B6 at -187 , and B8 at -166 ). The pattern of bands and intensities was, within experimental error, the same for the two cell lines tested (shown at the top of the lanes; lanes 1 vs. 3, 2 vs. 4). In addition, no significant difference was observed in the pattern of bands between untreated and dexamethasonetreated cells (lanes 1 vs. 2,3 vs. 4). Using oligonucleotide 670 , which primes upstream of oligonucleotide 749 , the same strong bands at -235 (B5), -226 (B3), and -215 (B1), were observed (lanes 7-10). With the exception of band B8 at position - 166, which lies in a region of high background, the bands observed with oligonucleotide 749 downstream of $\mathrm{Bl}$ were also observed with oligonucleotide 670 (B2-B6). In addition, bands upstream of -235 were detected at -240 (B7) and -255 (B9). The results obtained with oligonucleotide 1142 (lanes 13-16), which primes further upstream of oligonucleotide 670 , confirmed the presence of bands at -240 (B7) and -255 (B9), and showed additional bands at -276 (B11), -304 (B13), and other positions (one between B13 and B11, and three upstream of B13). The extension products obtained with oligonucleotide 1142 were verified with another primer (data not shown). The bands in lanes 13-16 denoted with asterisks are observed only with oligonucleotide 1142 and were scored as primer-specific artifacts. As with oligonucleotides 749 and 670, the pattern of bands and relative intensities was the same for both cell lines in both control and dexamethasone-treated cells.

The data demonstrate the existence of nucleosome translational frames both upstream and downstream of the Nuc-B position inferred from low resolution indirect end-labeling experiments (Richard-Foy and Hager 1987). Hereafter, we will refer to this stretch of the LTR either as Nuc-B or the Nuc-B region, and to specific nucleosomes in this region as Nuc-B frames.

The scans of selected lanes from primer extensions with oligonucleotides 749,670 , and 1142 (Fig. 3B) illustrate more clearly the differences in intensity of the extension products. Although $5^{\prime}$ boundaries to the Nuc-B frames were detected from about position -166 through -340 , it is evident that the most abundant frames lie within 50 bases of each other between -187 and -235 in the vicinity of the $5^{\prime}$ end of Nuc-B /shown schemati- 
A

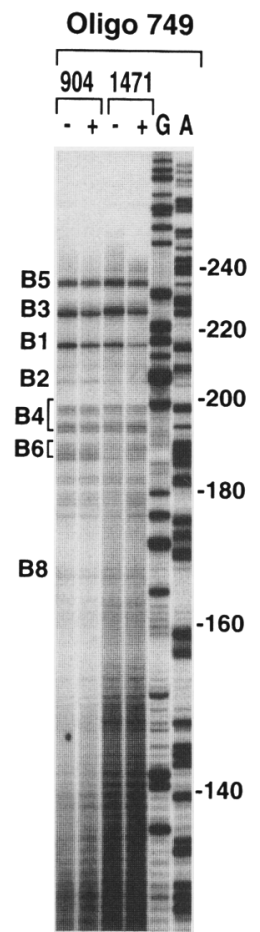

123456

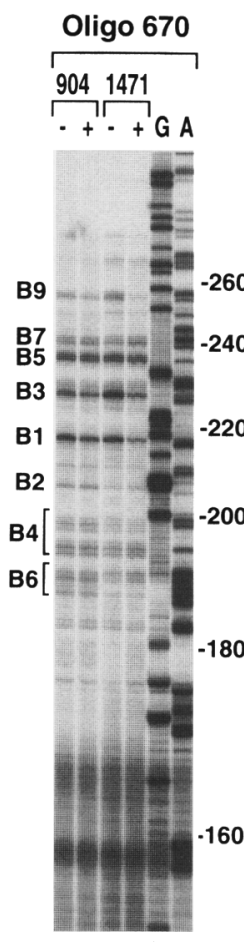

789101112

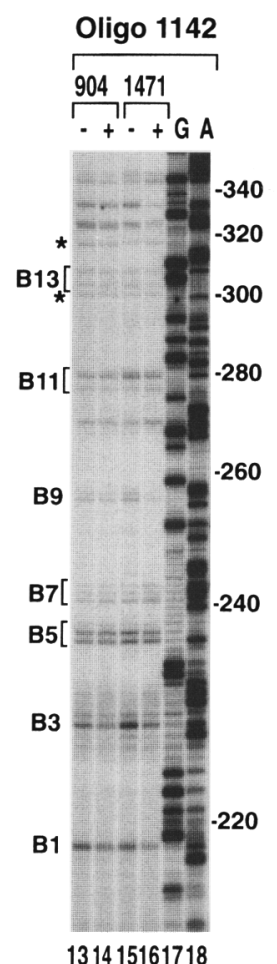

131415161718

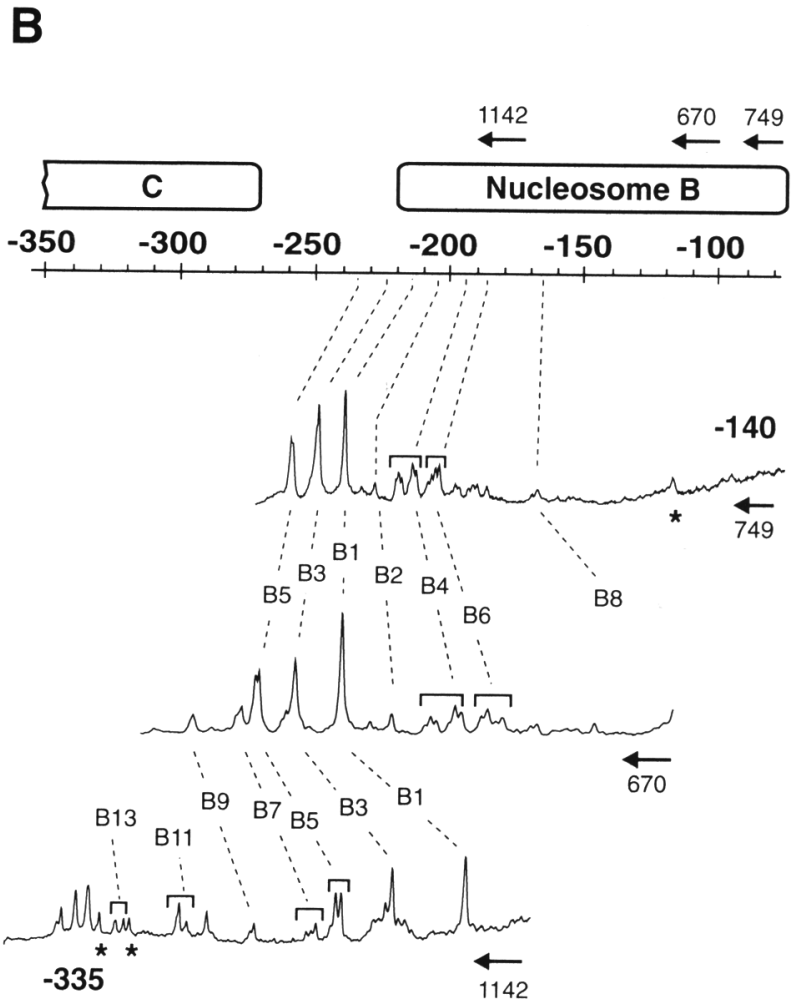

Figure 3. Determination of the $5^{\prime}$-nucleosome boundaries in the Nuc-B region of the LTR. $(A)$ Sequencing gel analysis of the primer extension products using Nuc-B-specific oligonucleotides priming in the 5 ' direction. (Lanes 1-6) Extensions with oligonucleotide 749; (lanes 7-12) extensions with oligonucleotide 670; (lanes 13-18) extensions with oligonucleotide 1142. $(-)$ Untreated cells; $\mid+$ ) dexamethasone-treated cells; $(G, A)$ dideoxy sequencing ladders. Numbers to the right of lanes 6,12 , and 18 indicate the nucleotide position in the MMTV LTR. Clusters of bands assigned to particular nucleosome frames are indicated to the left of lanes 1, 7, and 13 . Primer extension artifacts are marked with asterisks. $(B)$ Scans of selected lanes from $A$. (Top) Position and direction of priming of the oligonucleotide primers relative to the LTR sequence; the estimated low resolution position of selected nucleosomes is shown. (749) Scan of lane $1 ;(670)$ scan of lane $7 ;(1142)$, scan of lane 13 . Assignment of frames to specific peaks is shown. Region of the LTR scanned is from -140 to -335 . Gel and primer extension artifacts are marked under the scan with an asterisk.

cally on top). The additional bands between B6 and B8 (oligonucleotide 749 scan), and between B11 and B9 (oligonucleotide $1142 \mathrm{scan}$ ), remain unassigned to any frames because no similarly intense bands can be matched in the 3' direction (see below). The three bands upstream of B13 remain unassigned as no oligonucleotide primer has yet been obtained suitable for detection of the corresponding 3 ' ends.

The results from primer extension reactions using oligonucleotides designed to detect the 3 ' boundaries of the Nuc-B frames are shown in Figure 4A. A number of bands located throughout the -150 to -45 region were obtained with oligonucleotide 1150 (lanes $1-4$ ), with predominant bands at -86 (B5), -73 (B3), -64 (B1), -54 (B2), and -47 (B4). Upstream of B5, bands were observed at $-94(\mathrm{~B} 7),-103$ (B9), -127 (B11), and -151 (B13). The pattern of bands and relative intensities was about the same with both cell lines, and dexamethasone treatment of the cells did not affect the pattern. The small difference observed in the primer extension pattern in the B1B2 region of the untreated and dexamethasone-treated 1471.1 cells (lanes 3,4 ) was ascribed to differences in the preparations of nucleosomal DNA of these two samples. Bands B11, and B7 through B4 were confirmed with oligonucleotide 648 (lanes 7-10; see top of Fig. 4B for location of primer); B9 fell too close to a primer artifact (marked with an asterisk). In the Nuc-B region, the only bands not yet confirmed with independent primers are those defining the downstream boundaries of frames B9 and B13. Additional bands were observed with oligonucleotide 648 at -36 (B6) and -17 (B8). Using oligonucleotide 766 we confirmed the B6 and B8 bands (lanes 13-16). Interestingly, although primer 766 is capable of detecting $3^{\prime}$ boundaries to about position +45 in the LTR, we do not observe bands beyond -17 (B8). Unlike the results obtained in the $5^{\prime}$ direction, where frames continue into Nuc-C, albeit at a low frequency, Nuc-B frames do not merge into Nuc-A but simply stop at -17 . Such a discontinuity in frame progression suggests a boundary constraint in this region of the LTR.

Scans of selected lanes are shown in Figure 4B. The intensity of the extension products in the $3^{\prime}$ end of Nuc-B agree well with the intensities of the matched bands observed in the $5^{\prime}$ end. The most intense bands lie 
A

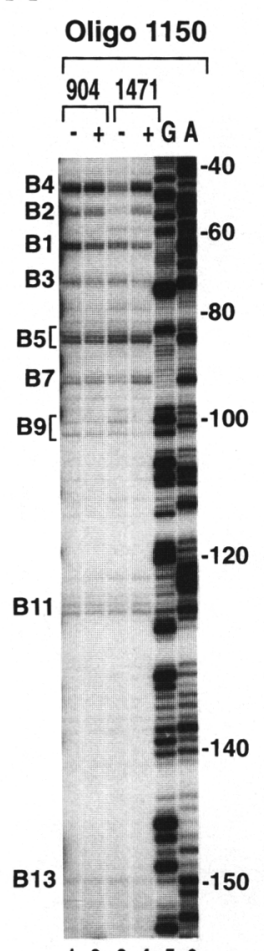

123456
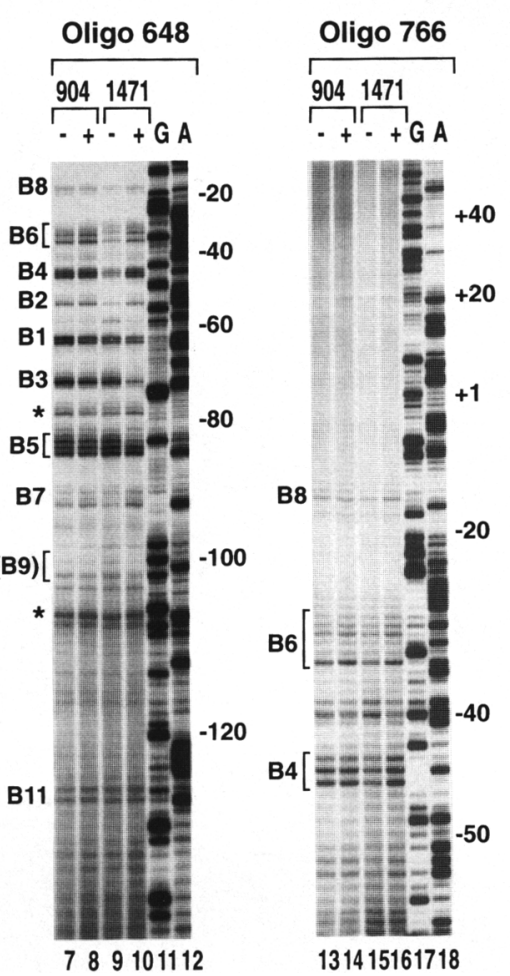

B
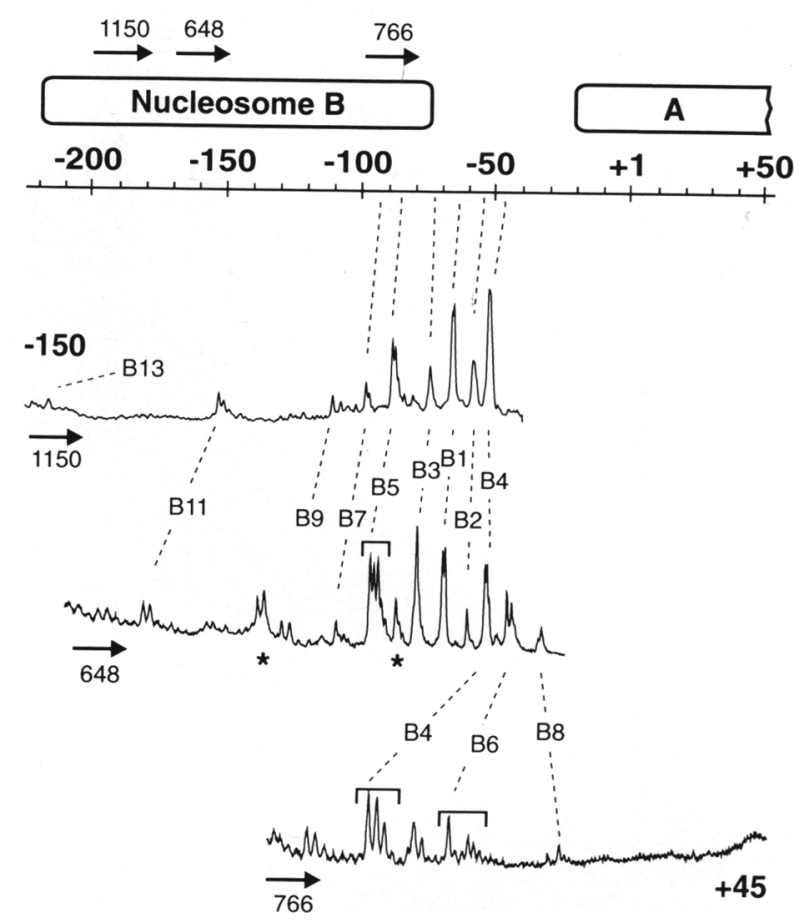

Figure 4. Determination of the $3^{\prime}$-nucleosome boundaries in the Nuc-B region of the LTR. $(A)$ Sequencing gel analysis of the primer extension products using Nuc-B-specific oligonucleotides priming in the $3^{\prime}$ direction. (Lanes $1-6$ ) Extensions with oligonucleotide 1150; (lanes 7-12) extensions with oligonucleotide 648; (lanes 13-18) extensions with oligonucleotide 766. Labeling of cells and treatments, nucleotide position, and frame assignments as in Fig. 3A. (B) Scans of selected lanes from $A$. (Top) Position and direction of priming of the oligonucleotide primers relative to the LTR sequence; the estimated low resolution position of selected nucleosomes is shown. (1150) Scan of lane $1 ;(648)$ scan of lane 7; (766) scan of lane 13. Assignment of frames to specific peaks is shown. Region of the LTR scanned is from -150 to +45 . Gel and primer extension artifacts are marked under the scan with an asterisk.

between -36 and -86 , clustered within 50 bases of each other as observed for the most intense bands in the $5^{\prime}$ end of Nuc-B. The intensity of the primer extension products reflects in large measure the occupancy of the nucleosome frames. The data indicate that the occupancy of frames is biased such that the most frequently occupied frames are found between -36 and -235 , in excellent agreement with the low resolution position of Nuc-B (Richard-Foy and Hager 1987; Bresnick et al. 1991).

\section{Determination of the Nuc-A boundaries}

The results obtained with Nuc-A-specific oligonucleotides priming in the $5^{\prime}$ direction are shown in Figure $5 \mathrm{~A}$. The scan of $5^{\prime}$ boundaries conducted with oligonucleotide 750 spans the +70 to -50 sequence of the LTR (lanes 1-4). A number of bands, and clusters of bands, were observed in both cell lines upstream of +40 through the -50 region, at $+42(\mathrm{~A} 10),+27(\mathrm{~A} 8),+17$ (A6), +6 (A4), -22 (A1), -39 (A3), and -50 (A5). The 5' end of the frame denoted $\mathrm{A} 2$ has been assigned tentatively to position -6 in the LTR. Two cell line-specific differences were observed in this region. The cluster of bands at -22 (A1) was relatively more intense in the 904.13 cells, indicating a high occupancy of the Al frame in this cell line, whereas the band at +25 (in frame A8) was much more intense in the 1471.1 cells (lane 4, marked by a closed arrow to the right of lane 6 ; seen in this gel only in the dexamethasone-treated sample because of a primer artifact). The higher intensity of the band at +25 could be explained by a higher occupancy of the A8 frame in the 1471.1 cells, or perhaps to slight differences in the translational position of A8 between the two cell lines; this point is not yet resolved. As in the case of Nuc-B, no significant changes in the relative intensities of the bands were detected in untreated versus dexamethasone-treated cells (lanes 1 vs. 2 , and 3 vs. 4 ). The difference in the $\mathrm{A} 2$ frame between the untreated and dexamethasone-treated 1471.1 cells was ascribed to variation in the preparation of the nucleosomal DNA (lanes 3,4). The intense signal in lanes 1 and 3 at around +25 is a primer extension artifact obtained sporadically with oligonucleotide 750 . Despite repeated primer extension attempts with this primer, we were unable to obtain results where all the samples lacked the strong artifact observed in this figure (lanes 1,3 ). There was no pattern to this strikingly strong band; on some occasions 
A

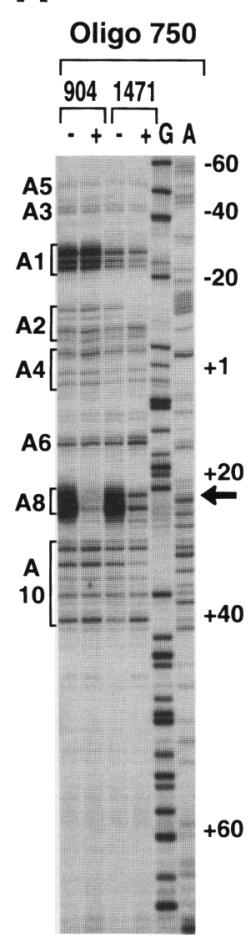

123456

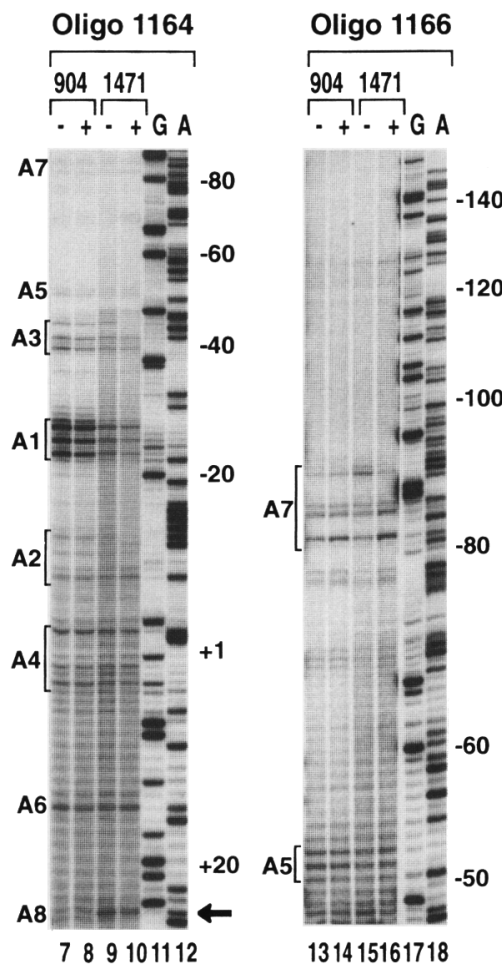

B

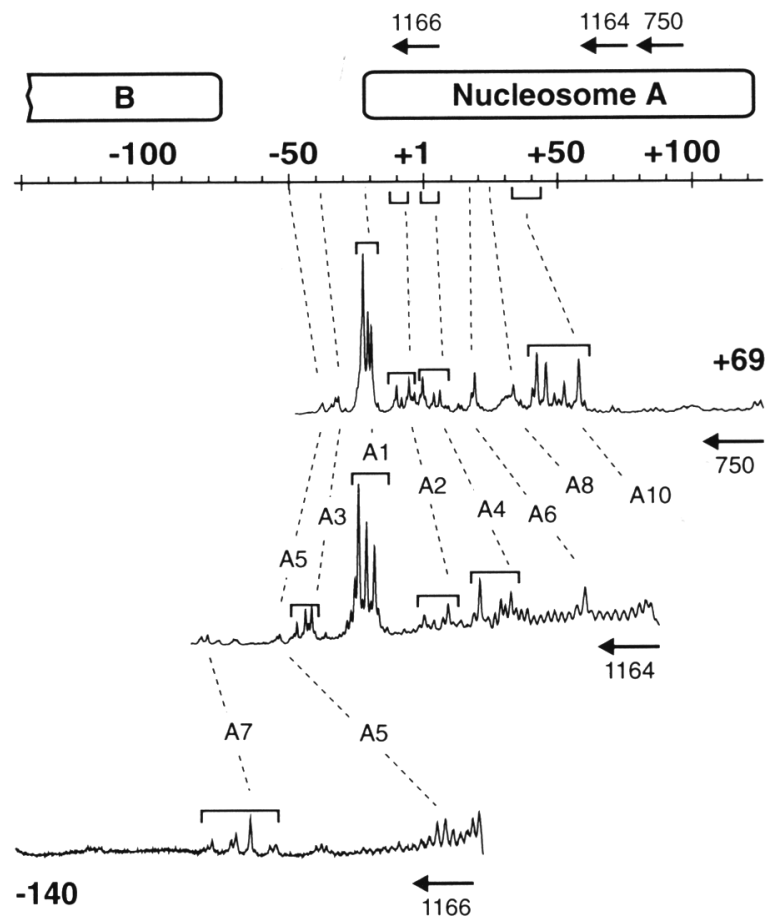

Figure 5. Determination of the $5^{\prime}$-nucleosome boundaries in the Nuc-A region of the LTR. (A) Sequencing gel analysis of the primer extension products using Nuc-A-specific oligonucleotides priming in the $5^{\prime}$ direction. (Lanes 1-6) Extensions with oligonucleotide 750; (lanes 7-12) extensions with oligonucleotide 1164; (lanes 13-18) extensions with oligonucleotide 1166. Labeling of cells and treatments, nucleotide position, and frame assignments as in Fig. 3A. The closed arrow to the right of lanes 6 and 12 marks band at +25 . $(B)$ Scans of selected lanes from $A$. (Top) Position and direction of priming of the oligonucleotide primers relative to the LTR sequence; the estimated low resolution position of selected nucleosomes is shown. (750) Scan of lane $2 ;(1164)$ scan of lane $7 ;(1166)$ scan of lane 13. Assignment of frames to specific peaks is shown. Region of the LTR scanned is from +70 to -140 .

it failed to appear in the uninduced samples, and at the same time it was clear and strong in the dexamethasonetreated samples. In addition, this band randomly appeared in both the dideoxy-A and dideoxy-G sequence ladders (data not shown).

Primer extension reactions conducted with oligonucleotide 1164, which primes in the $5^{\prime}$ direction upstream of oligonucleotide 750, are shown in lanes 7-10 (Fig. 5A; see top of Fig. 5B for position of primer). Although the background was high with this primer, it was possible to confirm the bands obtained with oligonucleotide 750 that comprise frames A6-A5. The difference in the relative intensity of the $\mathrm{Al}$ frame in the two cell lines was also evident with this primer. The band at +25 , assigned with oligonucleotide 750 to the A8 frame, was also confirmed with this oligonucleotide (closed arrow to the right of lane 12). A set of bands further upstream of A5 is now observable at -82 (A7). The A7 bands were confirmed with oligonucleotide 1166 (lanes 13-16), which primes upstream of oligonucleotide 1164. As expected from the results obtained in the Nuc-B region, where B frames do not merge into the A frames, no significant bands were seen upstream of A7 (at -82) using oligonucleotide 1166 , which is capable of detecting $5^{\prime}$ bound- aries to position -145 in the LTR. Scans of selected lanes (Fig. 6B) show more graphically the relative intensities of the different bands /the lack of significant bands/frames downstream of +40 (top scan, oligonucleotide 750), the low frequency and occupancy of frames upstream of -39 (center scan, oligonucleotide 1164), and the absence of observable bands above background in the region upstream of $A 7$ through nucleotide -145 in the LTR (bottom scan, oligonucleotide 1166)].

The results obtained with oligonucleotides priming in the 3 ' direction of Nuc-A complement very well the results observed for the $5^{\prime}$ ends (Fig. 6A). Primer extension with oligonucleotide 1165 (see top of Fig. 6B for position of primer) resulted in a relatively clean extension from +10 through +60 in the LTR (lanes $1,2,5,6$ ). The 3 ' end of frames A7, A5, and A3 were found at $+63,+98$, and +107 , respectively. Using oligonucleotide 757 , which primes downstream of oligonucleotide 1165 , resulted in the products shown in lanes 7 and 8 . The $3^{\prime}$ ends of frames A7, A5, and A3 were again detected, as well as the $3^{\prime}$ ends of frames A1, A2, and A4 at around $+122,+137$, and +150 , respectively. The bands comprising frame $\mathrm{Al}$ displayed different relative intensities in the two cell lines, as expected from the results obtained in the $5^{\prime}$ end. 
A

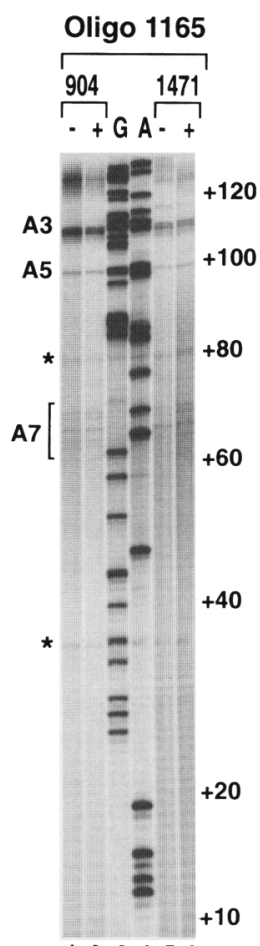

123456
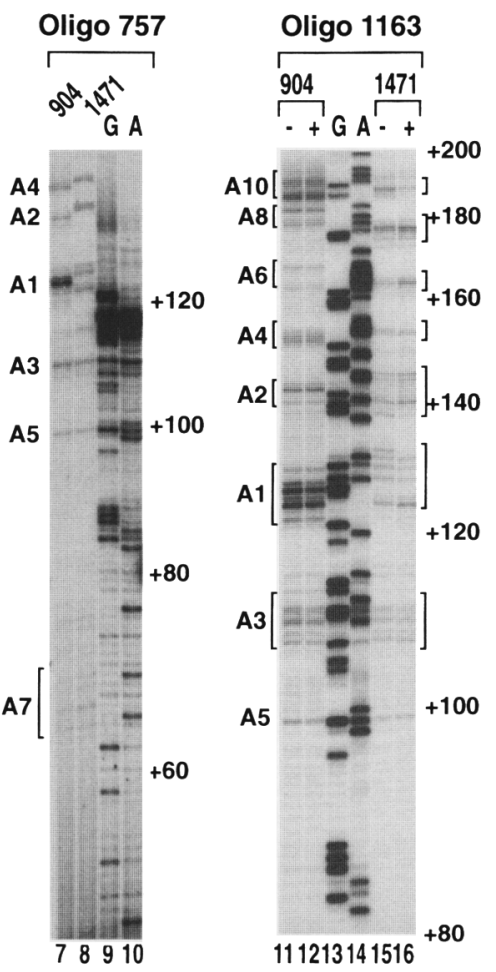

B

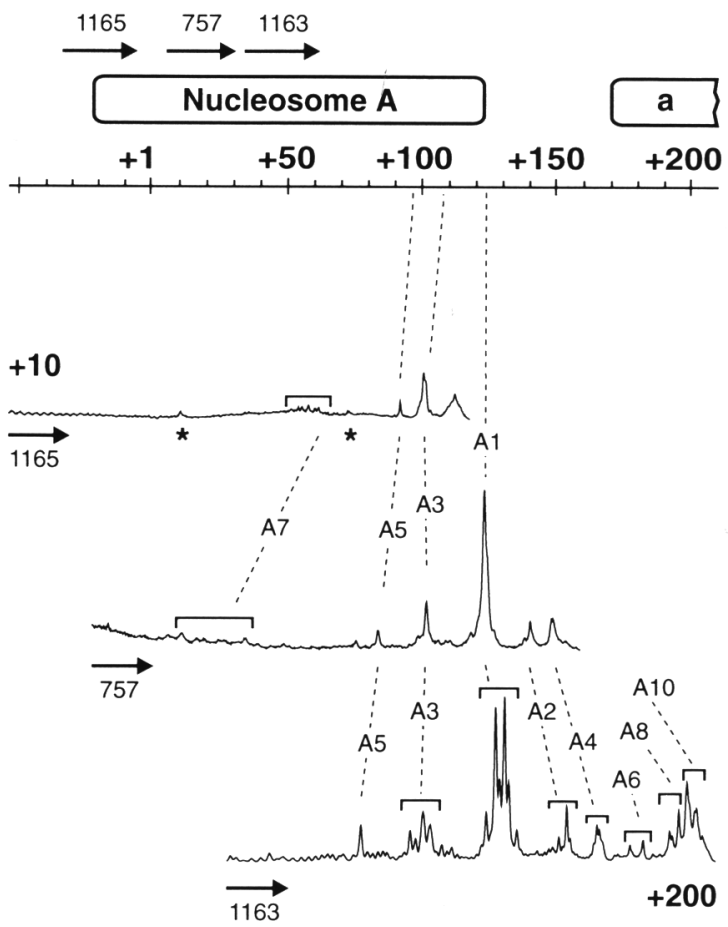

Figure 6. Determination of the $3^{\prime}$-nucleosome boundaries in the Nuc-A region of the LTR. (A) Sequencing gel analysis of the primer extension products using Nuc-A-specific oligonucleotides priming in the $3^{\prime}$ direction. (Lanes 1-6) Extensions with oligonucleotide 1165; (lanes 7-10) extensions with oligonucleotide 757; (lanes 11-16) extensions with oligonucleotide 1163. Labeling of cells and treatments, nucleotide position, and frame assignments as in Fig. 3A. Sequence ladders in lanes 9 and 10 were done with pm18 DNA restricted with BamHI; pm 18 is the BPV plasmid in 904.13 cells. Sequence ladders in lanes 13 and 14 were done with pm25, the BPV plasmid present in 1471 cells. Nucleotide assignments for the 904.13 extension products were do: 2 with sequence ladders using pm 18 (not shown). (B) Scans of selected lanes from A. (Top) Position and direction of priming of the oligonucleotide primers relative to the LTR sequence; the estimated low resolution position of selected nucleosomes is shown. (1165) Scan of lane 1; (757) scan of lane 7; (1163) scan of lane 11. Assignment of frames to specific peaks is shown. Region of the LTR scanned is from +10 to +200 . Gel and primer extension artifacts are marked under the scan with an asterisk.

The 3' ends detected downstream of A3 differed slightly in the two cell lines because of the specific locations where the MNase cuts the reporter DNA sequence (see below). The results with oligonucleotide 1163 (lanes $11,12,15,16)$ showed the $3^{\prime}$ ends of frames A6 at +161 , A8 at +171 in the 1471 cells and at +177 in the 904 cells, and $\mathrm{AlO}$ at +186 , in addition to the $3^{\prime}$ end of frames $\mathrm{A} 5, \mathrm{~A} 3, \mathrm{A1}, \mathrm{A} 2$, and $\mathrm{A} 4$. The only bands assigned to Nuc-A boundaries not verified by independent primers were $\mathrm{Al} 0$ in the $5^{\prime}$ direction, and those downstream of A4 in the $3^{\prime}$ direction. However, the $3^{\prime}$ ends of the frames downstream of A4 fall within the reporter sequence, which differ in the two cell lines used. Because the primer extension bands in this region differ in the two cell lines and reflect the substrate preference of MNase, it was deemed unnecessary to confirm these bands with independent primers.

The scans of selected lanes (Fig. 6B) show more clearly that upstream of $\mathrm{A} 3$ the frequency and occupancy of frames decreases drastically (1165 scan), and that Al is the major frame in 904 cells (757 and 1163 scans). We have not attempted to scan for nucleosome frames further downstream of $\mathrm{A} 10$ in the $3^{\prime}$ direction as there were no major frames downstream of $\mathrm{A} 10$ between +42 and +70 in the $5^{\prime}$ direction (see Fig. 5). Any frames in this region would have an occupancy similar to that of the A7 frame, which was very low as can be seen from the primer extensions with oligonucleotides 1166 (Fig. 5) and 1165 (Fig. 6). The major Nuc-A frames in the LTR are found between -40 and +180 , in good agreement with previous low-resolution estimates (Richard-Foy and Hager 1987; Bresnick et al. 1991). However, the clustering of frames is not as dramatic as in the case of Nuc-B.

The reporter sequences, 30S-ras in the 904 cell line, and the CAT gene in the 1471 cell line, begin downstream of frame A3 at nucleotide +118 . The location where the sequence of the constructs diverge and MNase cuts the reporters is shown in Figure 7. With the exception of frame A8, the position of the MNase cuts defining the $3^{\prime}$ ends of the Nuc-A frames in the two cell lines agree within 1-3 bases. The location of the $3^{\prime}$ cuts of frame $\mathrm{A} 8$ differ in the two cell lines possibly because the 


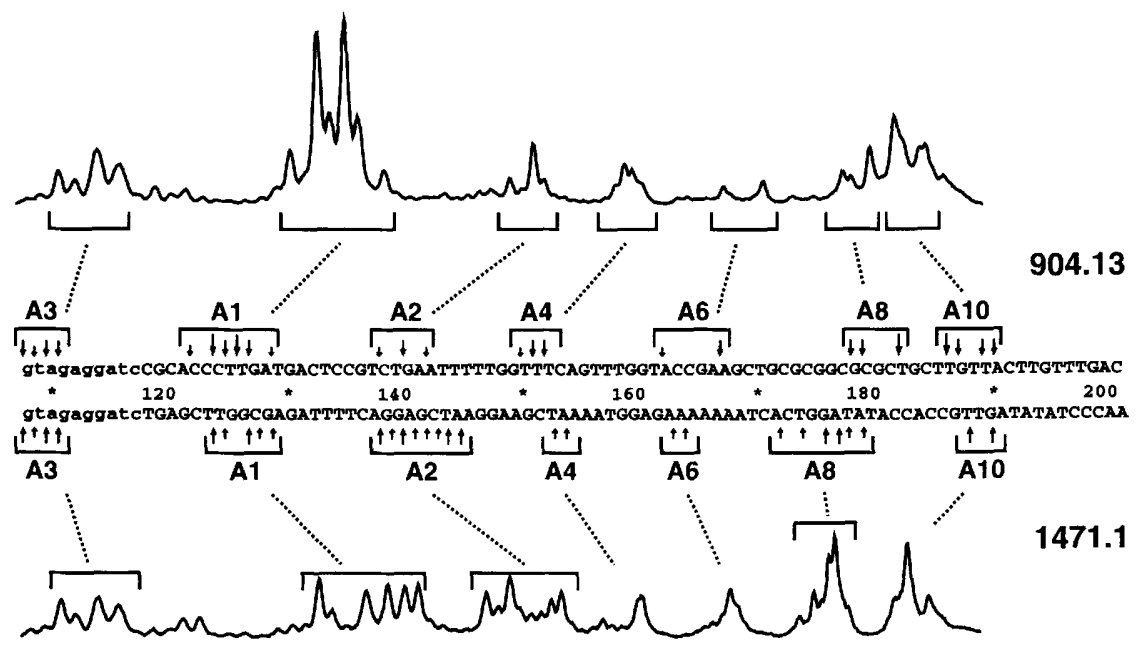

Figure 7. Location of the $3^{\prime}$ ends of the nucleosome frames in the Nuc-A region. A BamHI cloning linker is shown in lowercase letters. The first base of the reporter sequence is at nucleotide +118 . The top sequence, 904.13 , is from the 30 S element preceding ras. The bottom sequence, 1471.1 , is from the CAT gene in the plasmid pSV2CAT. Primer extension products are marked by arrows; the intensity of the band is represented by the size of the arrow on a scale of 1 to 3 . The actual DNA ends generated by MNase occur in the complement of the strand shown. Clusters of bands assigned to particular frames are bracketed. The scans of lanes 11 and 15 from Fig. 6A are shown, respectively, above and below the reporter sequences.
DNA sequence immediately upstream of A8 in the 904 cells is a poor substrate for the MNase, although we have not tested this directly.

\section{Discussion}

Previous work from this laboratory demonstrated that the MMTV LTR is highly ordered at the chromatin level (Richard-Foy and Hager 1987). The MNase cleavage sites in the promoter-proximal region (nucleosome A/B) were mapped subsequently at base-pair resolution, and shown to be conserved in a variety of promoter-reporter configurations (Bresnick et al. 1992b; Mymryk et al. 1995). Determination of nucleosome positions, by primer extension assays using DNA obtained from native core particles, suggested the presence of major translational frames in the A/B region of the LTR (Bresnick et al. $1992 \mathrm{~b}$ ), but the presence of additional primer extension products complicated the assignments of nucleosome boundaries.

In the current work, we have addressed two major difficulties associated with mapping in vivo nucleosome positions by this methodology. Specifically, mobility of histone octamers on DNA (Pennings et al. 1991; Meersseman et al. 1992), and nicking of nucleosomal DNA during MNase digestion, would result in incorrect assignments. Reversible cross-linking of histones to DNA before cell disruption prevents potential rearrangement of nucleosomes during chromatin preparation (Jackson 1978; Jackson and Chalkley 1981; Solomon and Varshavsky 1985); the contribution from nicked DNA is eliminated by isolation of core-length single-stranded DNA (Buttinelli et al. 1993; Venditti et al. 1994). We find that the multiple primer extension products observed previously with DNA isolated from native core particles are still seen using our preparations of single-stranded mononucleosomal DNA obtained from fixed cells. The pattern of bands and relative intensities in the Nuc-A region is virtually identical, underscoring the reproducibility of these results. However, we do observe some differences between both sets of data in the Nuc-B re- gion; the relative intensities of some of the bands differ, and some very strong primer extension products are observed in native core particle DNA preparations that are missing from our present preparations from fixed cells. We ascribe this difference to the complications associated with mapping nucleosome positions by our previous methodology, as mentioned above. Our present results indicate the presence of multiple frames in the A/B region of the LTR. In fact, the distance between the major primer extension products is long enough to rule out effectively the existence of a unique nucleosomal frame in either the A or B regions of the LTR. The cluster of frames that we have now shown to exist in the promoter region of MMTV includes the two frames that were mapped previously as the major positions; we have now designated these frames $\mathrm{B} 3$ and $\mathrm{Al}$.

The distribution of nucleosome frames in the promoter region of MMTV is summarized in Figure 8. The approximate boundaries of the different frames are operationally defined by the cuts generated by MNase. Within experimental error, the results obtained in the Nuc-B region are identical for the 904.13 and 1471.1 cell lines. The extension products in the Nuc-B region display strikingly different intensities, which indicates a strongly biased frame occupancy, depicted in Figure 8 by the thickness of the line representing each frame. The more frequently occupied frames are grouped in a cluster centered on the position designated nucleosome $B$. The distribution of Nuc-A frames displays similarities to what is observed in the Nuc-B region. Again, within experimental error, but with the clear exception of one frame (Al), the positions of the frames and the relative occupancies are the same for both cell lines. The Nuc-A frames are clustered and centered within the region designated nucleosome $\mathrm{A}$. The only significant difference between the cell lines is observed in frame $A 1 ; A l$ is clearly the dominant frame in the Nuc-A region of 904.13 cells, whereas it displays about the same occupancy in the 1471.1 cells as frames A8 and A10. It remains a formal possibility that some of the low-level nucleosomes we observe are attributable to coincidental 
Figure 8. Summary of nucleosome frame positions in the Nuc-B and Nuc-A region of the MMTV LTR. (Top) Binding sites of some of the known transcription factors that regulate the expression of MMTV. The estimated positions at low resolution of nucleosomes in this region are also shown. (Bottom) Nucleosome frames defined in this work. The approximate positions of the $5^{\prime}$ and $3^{\prime}$ ends of the named frames are based on the ends generated by MNase. To assess the extent of occupancy of each frame, the integrated intensities of the bands defining each frame were ranked on a scale of $1-5$. With the exception of two frames in the Nuc-B region, the rank-

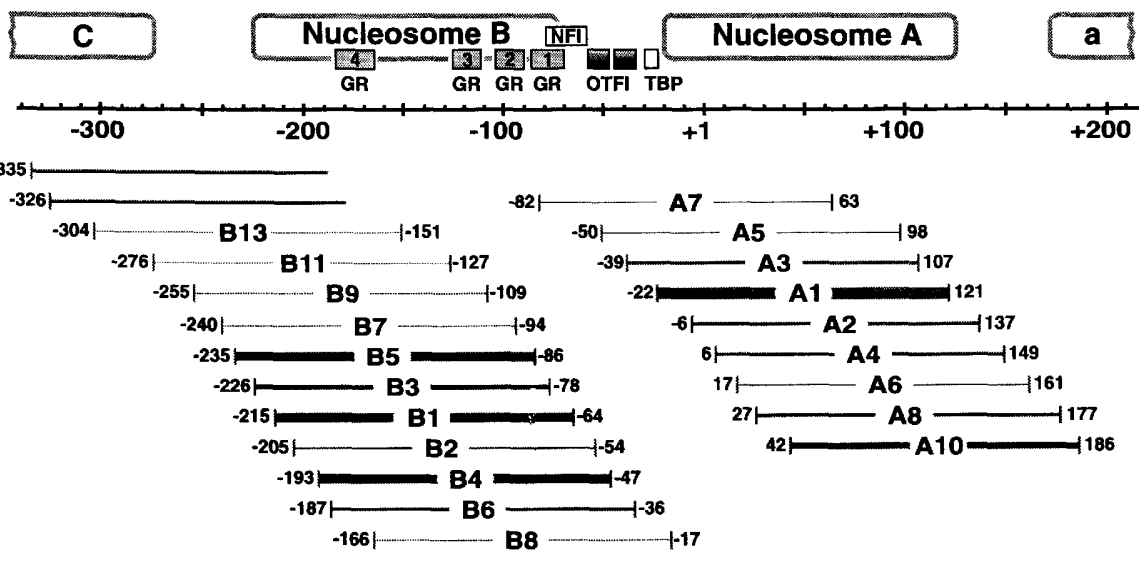
ings of the upstream boundaries matched to within \pm 0.5 the rankings of the downstream boundaries. The estimated relative occupancy of each frame in the 904.13 cells is represented on this scale by the thickness of the line; the scales in the A and B region are not necessarily the same, as there was no overlap between Nuc-A and Nuc-B boundaries in the primer extension assays.

double-stranded MNase cuts spaced 150 bases apart. However, the agreement between our present results and those obtained previously, using DNA extracted from isolated native core particles (Bresnick et al. 1992b), makes this possibility unlikely.

This bias in the occupancy of frames accounts very well for the positioning observed at low resolution using both MNase and MPE-Fe(II) in indirect end-labeling experiments (Richard-Foy and Hager 1987). In addition, the pattern of restriction enzyme access observed previously can be accounted for by the nucleosome frame distribution we report here (Archer et al. 1991). Furthermore, recently we have analyzed quantitatively the restriction enzyme accessibility of the promoter, and consistent with our present results, there are no restriction sites that are either completely occluded or completely accessible (G. Fragoso, W. Pennie, S. John, and G. Hager, unpubl). However, there are enzyme sites in this region that were not examined previously and that display accessibilities that do not conform to either the Nuc-A or Nuc-B frame occupancies. Although differences in the specific activity of restriction enzymes toward specific regions of nucleosomal substrates has been reported (Tack et al. 1981; Linxweiler and Horz 1984), there might be factors besides the translational position of nucleosomes that further affect the accessibility at specific sites of the LTR.

An important aspect of the positions of the different frames in the Nuc-A and Nuc-B regions is the discontinuity observed in the A-B linker. This is particularly striking as the progression of Nuc-B frames stops abruptly in the $3^{\prime}$ direction toward Nuc-A, whereas it continues in the $5^{\prime}$ direction toward Nuc-C. This interruption in the progression of frames from A to B indicates a boundary constraint that in turn could set a nucleosome positioning phase. In this regard, the organization of nucleosome frames we observe is similar to what is expected from a statistical positioning model (Kornberg 1981; Kornberg and Stryer 1988) in that a boundary constraint has a primary influence on positioning. However, neither the Nuc-A nor the Nuc-B distributions are statistical. Further constraints appear to operate below the level of the boundary; on the basis of in vitro data, we suggest that the bendability of the DNA exerts an influence at this lower level (see below).

The DNA sequence at -10 through -30 contains runs of both $T$ and $A$ residues, which have been observed previously to occur preferentially at edges of nucleosome cores, away from the axis of dyad symmetry (Satchwell et al. 1986). These sequences could act as a translational constraint, as was suggested previously for Nuc-A/ Nuc-B dinucleosomal reconstitutes (Pina et al. 1990a). This would explain the looseness of the boundary effect, in that we observe nucleosome frames that, albeit at a low frequency, penetrate the boundary. Alternatively, or perhaps in addition to, DNA-binding proteins that interact with sequences in the A-B linker might act as phasing factors (Fedor et al. 1988; Roth et al. 1990; Shimizu et al. 1991; Venditti et al. 1994). Because this linker region includes the TATA box and binding sites for the immediate proximal promoter factors, some member of the transcription initiation complex may serve such a role. Although steroid hormone-dependent recruitment of proteins to the promoter has been documented extensively (Cordingley et al. 1987; Archer et al. 1992; Truss et al. 1994), the presence of a subset of factors on the uninduced promoter is possible. The prospect of nonhistone protein factors affecting nucleosome frame occupancy must be considered in light of the difference we observe in the frequency of the Al frame between both cell lines. The DNA sequence comprising this frame differs in these cells only in the last ten $3^{\prime}$-end residues; it seems unlikely that this small difference in DNA sequence could so dramatically affect the Al frame occupancy.

Several examples of specific rotational positioning of nucleosome cores in vivo have been reported (Zinn and Maniatis 1986; Thomas and Elgin 1988; Ewel et al. 1990; 
Pfeifer and Riggs 1991; Shimizu et al. 1991; Truss et al. 1993). Our results are not inconsistent with the possibility that some of the frames we detect in vivo are rotationally in phase. Previous studies have shown that Nuc-B DNA bends preferentially in one direction (Pina et al. 1990a). In addition, reconstitution of the Nuc-B DNA with histones has resulted in rotationally positioned nucleosomes (Pina et al. 1990b; Perlmann and Wrange 1988; Bresnick et al. 1991), although there has been disagreement on the precise translational position of Nuc-B in these experiments (Perlmann and Wrange 1988; Pina et al. 1990b; Archer et al. 1991; Bresnick et al. 1991; T. Richmond, pers. comm.). In a separate paper (Roberts et al. 1995), we show that nucleosomes reconstituted in vitro with Nuc-B DNA are resolved into multiple species by gel electrophoresis. Three of the resolved reconstitutes were found to differ in translational phase while exhibiting the same rotational phase. Moreover, a second rotational phase that was evident in the unresolved reconstitute was clearly demonstrated in independent reconstitutes prepared with a smaller $(<150 \mathrm{bp})$ fragment of DNA from the Nuc-B region (Roberts et al. 1995). Thus, the DNA sequence of Nuc-B, as has become evident in other systems (Hansen et al. 1989; Dong et al. 1990; Meersseman et al. 1992; Buttinelli et al. 1993), supports multiple nucleosome positions in vitro. It is especially noteworthy that a crude, unresolved, in vitro Nuc-B reconstitute containing cores in at least three and very likely five different positions in two rotational phases, nevertheless manifests a distinct 10-base modulation in the hydroxy radical cutting profile (Roberts et al. 1995). On the basis of our findings in the MMTV system, we suggest strongly that the observation of a 10-base cleavage periodicity in vivo does not provide rigorous evidence for a unique nucleosome position, and that the possibility of further heterogeneity in these systems must be considered.

It now appears that several factors contribute to positioning of nucleosomes in the promoter region of MMTV. We suggest that the family of available frames in the promoter of MMTV is constrained translationally at one end by the A-B linker, either by structural features unique to this DNA sequence (Satchwell et al. 1986), or by DNA-binding factors that affect nucleosome assembly in this region (Fedor et al. 1988; Roth et al. 1990; Shimizu et al. 1991; Venditti et al. 1994). Anisotropic bendability of the DNA (Trifonov and Sussman 1980) may further restrict the histone octamer to a subset of frames in a short stretch of DNA, although multiple rotational settings may occur (Drew and Calladine 1987; see discussion in Roberts et al. 1995). The combined effect of these mechanisms results in the assembly of what appears in the MMTV population as a series of nucleosome clusters across the LTR. Preliminary studies on the Nuc-F region of the LTR are consistent with this model (G. Fragoso, S. John, and G.L. Hager, unpubl.); that is, this region also contains a series of boundary-constrained nucleosome frames. The difference we observe in the occupancy of the Al frame between the 1471.1 and the 904.13 cells could be attributable to another boundary constraint downstream of the Nuc-A region in the reporter sequence of the 904.13 cells; proteins present in preparations of nuclear matrices show an affinity for this DNA sequence (Adom et al. 1992), and conceivably could influence nucleosome frame occupancy in their vicinity.

The structure that we have determined for the promoter region of the LTR is of particular interest with regard to basal MMTV regulation. Both MMTV provirus and LTR-driven reporter constructs display varying levels of basal transcriptional activity detectable by run-on transcription (Stallcup and Washington 1983; Pennie et al. 1995), steady-state RNA levels (Hynes et al. 1983; Majors and Varmus 1983; Ucker et al. 1983), and production of protein (Lefebvre et al. 1991; Hartig et al. 1993). In addition, basal activity can be detected both when MMTV is in a stably integrated state and transfected transiently (Smith et al. 1993). One of the immediate proximal promoter factors, NF-I, has been implicated in the basal regulation of MMTV (Buetti et al. 1989; Kalff et al. 1990; Toohey et al. 1990), but NF-I does not bind its cognate site in nucleosomal Nuc-B reconstitutes (Pina et al. 1990b; Archer et al. 1991). It is conceivable that NF-I binds a specific configuration of Nuc-B nucleosomes that was not reproduced previously in vitro. In light of our results, however, it is also possible that NF-I binds the fraction of molecules in the MMTV population that contains the NF-I site in an accessible region. Consistent with this idea, we have determined recently by in vivo exonuclease footprinting that the NF-I site is occupied in the basal promoter of a fraction of the MMTV molecules (G. Fragoso, S. John, and G.L. Hager, unpubl.); a similar result has been obtained recently by Hartig and Cato (1994). Currently, we are developing methodologies to determine quantitatively the level of occupancy in both the uninduced and hormone-stimulated promoter.

Hormonal stimulation of MMTV results in nuclease hypersensitivity on the Nuc-B region of the LTR (Zaret and Yamamoto 1984; Peterson 1985; Richard-Foy and Hager 1987; Archer et al. 1991). In the two cell lines used in the present work, maximal hypersensitivity is attained after a $1-\mathrm{hr}$ incubation with dexamethasone (Archer et al. 1994; G. Fragoso, W. Pennie, S. John, and G. L. Hager, unpubl.). We do not observe a significant change in the number or relative intensity of the primer extension products that define the nucleosome frames in the Nuc-B and Nuc-A regions of the LTR. The small differences we found were not consistent across cell lines; in addition, small differences in $5^{\prime}$ or $3^{\prime}$ boundaries between untreated and dexamethasone-treated cells were not matched in the corresponding $3^{\prime}$ or $5^{\prime}$ boundaries. Previously, we have presented evidence suggesting that the core histones remain associated with the MMTV promoter upon steroid hormone treatment (Bresnick et al. 1992a); in contrast, association of the linker histone $\mathrm{Hl}$ with the LTR is affected significantly. Consistent with that work, our present results do not show a general loss of core histones from either the Nuc-B or the Nuc-A region. However, loss of histones could have been detected only in two possible cases. 
Glucocorticoid receptor (GR) interacts productively with all the possible Nuc-B frames and all the templates in the population respond to the steroid simultaneously /which does not occur, see below), or alternatively, GR only interacts with a specific configuration of Nuc-B, in which case histone loss from this subset of frames would have been detected as a change in the occupancy of these frames relative to their neighbors. On the other hand, in the case where GR can interact productively with all the Nuc-B frames but not all the MMTV templates bind or respond to GR at one time, we would be unable to detect a loss of core histones if it occurred; the total Nuc-B occupancy would decrease without affecting the relative frame occupancy. In addition, if the hypersensitive MMTV subpopulation is in a steady-state, transition intermediates with substoichiometric amounts of histones might be present at a concentration too low to significantly affect the relative nucleosome frame occupancy that we detect with this assay. Future efforts will be directed to the enrichment or isolation of GR-containing templates to define unambiguously the molecular composition and chromatin architecture of the hypersensitive MMTV promoter.

The finding of multiple frame occupancy may be related directly to the observed heterogeneity in the hormonal response of MMTV. The MMTV B region does not convert fully to the DNase I hypersensitive phenotype, even in low MMTV copy number cell lines overexpressing GR (Vanderbilt et al. 1987). The dexamethasone-dependent change in restriction enzyme accessibility at various sites in the Nuc-B region of the 904.13 cells is $15 \%-20 \%$, suggesting that this percent of the templates responds to the steroid (G. Fragoso, W. Pennie, S. John, and G.L. Hager, unpubl.). This is in contrast to other systems, such as the yeast PHO5 gene, where the change in enzyme accessibility upon induction is $95 \%-100 \%$ (Almer et al. 1986). Heterogeneity in the functional response has also been described at the single cell level in cells carrying one copy of an MMTV LTR- $\beta$-gal construct (Ko et al. 1990). After cell division, activation of the promoter in daughter cells led to a wide variation in response of the $\beta$-gal reporter. The maximal level of response in individual cells was observed even at the lowest hormone concentrations used; conversely, unresponsive cells were present in populations of cells stimulated with high concentrations of hormone. One interpretation consistent with these findings is that the promoter's nucleoprotein organization after replication is a major determinant of activation potential. Alternate nucleosome positioning could contribute to this potential variation in response.

There is now a substantial body of evidence that indicates that eukaryotic promoters can acquire a precise and reproducible nucleoprotein architecture, and that the interaction of the soluble transcription apparatus with the template is strongly modulated by these structures. The impact of nucleosome positioning on factor recruitment to the MMTV promoter remains an important experimental paradigm in understanding transcriptional regulation in these complex systems.

\section{Materials and methods}

\section{Cell lines and DNAS}

Cells were maintained as monolayers grown in Dulbecco's modified Eagle medium (DMEM) containing 10\% bovine serum. Twenty-four hours before use, cells were switched to DMEM lacking phenol-red and containing $10 \%$ charcoalstripped serum. When required, treatment with dexamethasone was for $60 \mathrm{~min}$ at a concentration of $0.5 \mu \mathrm{M}$.

The cell lines have been described previously (Richard-Foy and Hager 1987; Archer et al. 1994). Briefly, lines 904.13 and 1471.1 were obtained by transfecting $\mathrm{C} 127$ mouse mammary cells with BPV-based MMTV reporter plasmids. The MMTV LTR drives the CAT gene in plasmid pm25, used for the generation of the 1471.1 cell line, and it drives v-Ha-ras in the plasmid pm18, used for the generation of 904.13. The ras gene in this construct is embedded within the DNA of a virus-like $30 \mathrm{~S}$ element.

The DNA sequence of the LTR in the chromatin region analyzed is in the GenBank file MMTPRO (accession no. J02274), the transcription initiation site is at nucleotide 1227. Reporter genes were inserted into a BamHI site in a cloning linker that begins at +108 relative to the transcription initiation site. The $30 \mathrm{~S}$ sequence preceding ras in plasmid pm 18 has the GenBank accession number M91235. The CAT gene in pm25 was derived from pSV2CAT (accession no. M77788).

\section{Formaldehyde cross-linking}

Analytical reagent grade formaldehyde $137 \%$ solution containing $10 \%$ methanol) was treated essentially as described (McGhee and von Hippel 1975). On the day it was used, $10 \mathrm{ml}$ of formaldehyde was incubated $30 \mathrm{~min}$ in a boiling water bath, and deionized by chromatographing twice over a column containing 1.5 gram of mixed bed resin [AG 501-X8 (D), Bio-Rad]. Cells growing as monolayers were fixed by replacing the medium with $1 \%$ formaldehyde in DMEM, and incubating for 10 min at $37^{\circ} \mathrm{C}$ (Solomon and Varshavsky 1985). Dexamethasonetreated cells were cross-linked after a 1 -hr induction, when maximal hypersensitivity is observed in a restriction enzyme access assay (CAT activity in the 1471.1 cells is induced 8- to 10-fold at $4 \mathrm{hr}$ of dexamethasone treatment, much greater at later times). The fixed cells were rinsed twice with cold PBS, collected by scraping, and centrifuged.

The extent of histone-DNA cross-linking was assessed essentially as described by Jackson (1978), with some modifications. Briefly, nuclei were prepared from cells fixed with formaldehyde as described above, and the fixed chromatin solubilized by sonication. Acid extraction was performed with $0.4 \mathrm{~N} \mathrm{H}_{2} \mathrm{SO}_{4}$ and the acid soluble and insoluble fractions analyzed by gel electrophoresis. This analysis showed that $>60 \%$ of the total core histone was cross-linked to the DNA (data not shown). This extent of cross-linking was deemed adequate considering that an octamer may not need more than one histone-DNA cross-link to be fixed in place $(10 \%-15 \%$ cross-linking).

\section{Preparation of nuclei and enzymatic digestion}

The harvested cells were resuspended and disrupted in a Dounce homogenizer with an " $\mathrm{A}$ " pestle in $0.3 \mathrm{M}$ sucrose, $2 \mathrm{mM}$ $\mathrm{MgAc}_{2}, 3 \mathrm{mM} \mathrm{CaCl}_{2}, 1 \%$ Triton X-100, and $10 \mathrm{~mm}$ HEPES / $\mathrm{pH}$ 7.8 ). Homogenates were centrifuged at $1000 \mathrm{~g}$ for $15 \mathrm{~min}$ in a tabletop centrifuge through a pad consisting of $25 \%$ glycerol, 5 $\mathrm{mM} \mathrm{MgAc} \mathrm{C}_{2}, 0.1 \mathrm{~mm}$ EDTA, and $10 \mathrm{~mm}$ HEPES (pH 7.4), and resuspended in the same buffer at an $\mathrm{OD}_{260}$ of $\sim 200$. Aliquots from the fixed nuclei were taken for absorbance measurements; 
Multiple nucleosome frames on the MMTV LTR

Table 1 Oligonucleotide primers used to determine the nucleosome boundaries in the $A$ and B region of the MMTV LTR

\begin{tabular}{|c|c|c|c|c|c|c|c|c|c|c|c|c|}
\hline \multirow{2}{*}{$\begin{array}{l}\text { Oligonucleotide } \\
\text { no. } \\
749\end{array}$} & \multicolumn{10}{|c|}{ Sequence } & \multirow{2}{*}{$\begin{array}{l}\begin{array}{l}5^{\prime} \\
\text { end }\end{array} \\
-78\end{array}$} & \multirow{2}{*}{$\frac{\text { Orientation }}{-}$} \\
\hline & AAG & $\mathrm{AAC}$ & ATA & GGA & AAA & TAG & AAC & $\mathrm{ACT}$ & $\mathrm{CAG}$ & & & \\
\hline 670 & TCA & GAG & CTC & AGA & TCA & GAA & $\mathrm{CCT}$ & TTG & ATA & $\mathrm{CC}$ & -101 & - \\
\hline 1142 & AGT & TTG & TAA & $\mathrm{CCA}$ & AAA & $\mathrm{ACT}$ & $\mathrm{TAC}$ & TTA & A & & -176 & - \\
\hline 1150 & TTA & AGT & AAG & TTT & TTG & GTT & $\mathrm{ACA}$ & $\mathrm{AAC}$ & $\mathrm{T}$ & & -200 & + \\
\hline 648 & TTC & TTA & AAA & CGA & GGA & TGT & GAG & ACA & AGT & GG & -174 & + \\
\hline 766 & GAG & TGT & TCT & ATT & TTC & CTA & TG & & & & -102 & + \\
\hline 750 & TGC & GGG & GGG & $\mathrm{ACC}$ & CTC & TGG & AA & & & & +98 & - \\
\hline 1164 & AAG & GAT & AAG & TGA & CGA & GCG & GA & & & & +74 & - \\
\hline 1166 & TGC & AAG & TTT & $\mathrm{ACT}$ & CAA & AAA & ATC & AGC & $\mathrm{ACT}$ & C & +3 & - \\
\hline 1165 & TAA & $\mathrm{ACC}$ & AAG & ATA & TAA & AAG & AGT & GCT & GAT & $T$ & -42 & + \\
\hline 757 & $\mathrm{CAG}$ & TCC & TAA & CAT & TCA & $\mathrm{CCT}$ & $\mathrm{CT}$ & & & & +5 & + \\
\hline 1163 & TGT & GTC & TGT & TCG & $\mathrm{CCA}$ & TCC & CG & & & & +33 & + \\
\hline
\end{tabular}

the absorbance was read after a 20 -min proteinase $\mathrm{K}$ digestion followed by a $30-\mathrm{min}$ incubation at $60^{\circ} \mathrm{C}$ to partially reverse the formaldehyde cross-links. Digestions with MNase were conducted in $25 \mathrm{~mm} \mathrm{KCl}, 4 \mathrm{~mm} \mathrm{MgCl} 2,1 \mathrm{~mm} \mathrm{CaCl}{ }_{2}, 12.5 \%$ glycerol, and $50 \mathrm{~mm}$ Tris- $\mathrm{Cl}(\mathrm{pH} 7.4)$, for $10 \mathrm{~min}$ at $37^{\circ} \mathrm{C}$ at an enzyme concentration of $500 \mathrm{U} / \mathrm{ml}$ and nuclei at an $\mathrm{OD}_{260}$ of 100. MNase digestions were terminated with an equal volume of $2 \%$ SDS, $0.2 \mathrm{M} \mathrm{NaCl}, 10 \mathrm{~mm}$ EDTA, $10 \mathrm{~mm}$ EGTA, and $50 \mathrm{~mm}$ Tris- $\mathrm{Cl}(\mathrm{pH} 8)$ and further digested with proteinase $\mathrm{K}$ at 100 $\mu \mathrm{g} / \mathrm{ml}$ for $2 \mathrm{hr}$ at $37^{\circ} \mathrm{C}$. Digests were incubated for $6 \mathrm{hr}$ at $60^{\circ} \mathrm{C}$ to fully reverse the protein-DNA cross-links (Solomon and Varshavsky 1985), extracted with phenol-chloroform, and the DNA recovered by ethanol precipitation. Samples were digested with $125 \mu \mathrm{g} / \mathrm{ml} \mathrm{RNase} \mathrm{A}$ and $1500 \mathrm{U} / \mathrm{ml}$ of RNase T1 in $0.2 \%$ Sarkosyl, $10 \mathrm{~mm}$ EGTA, and $10 \mathrm{~mm}$ Tris- $\mathrm{Cl}(\mathrm{pH} 8)$, for $2 \mathrm{hr}$ at $37^{\circ} \mathrm{C}$, phenol-chloroform extracted, precipitated with alcohol, and dissolved in $10 \mathrm{~mm}$ EGTA in TE.

\section{Preparation of mononucleosomal DNA}

Nuclease digests were fractionated in $5 \%$ acrylamide, $0.7 \%$ agarose composite gels in Tris-borate-EDTA buffer containing 0.1 $\mu \mathrm{g} / \mathrm{ml}$ ethidium bromide. Small strips from the gel were removed and the DNA visualized by transillumination with UV. The position of mononucleosomal DNA was marked and bands were cut out from the portions of the gel that were not irradiated, eliminating potential UV damage to the DNA. The DNA was eluted from the gel, chromatographed through an ion exchange resin (NACS-52, BRL), and recovered by precipitation with one volume of isopropanol. To prepare full-length, singlestranded mononucleosomal DNA, the samples were phosphorylated with T4 kinase using $\left[\gamma^{-32}\right.$ P]ATP at $440 \mu \mathrm{M}$ and a specific activity of $3.1 \mathrm{Ci} / \mathrm{mmole}$. The labeled DNA was electrophoresed in a denaturing $6 \%$ acrylamide, $8.3 \mathrm{M}$ urea, Tris-borateEDTA gel, and visualized by autoradiography. The center portion of the nucleosomal band was excised and the DNA eluted, chromatographed through NACS, and recovered by precipitation with one volume of isopropanol in the presence of $10 \mu \mathrm{g}$ of carrier RNA. The DNA amount was estimated by the radioactivity recovered. DNA was treated with calf intestinal phosphatase, extracted with phenol-chloroform, and precipitated twice, first with isopropanol and then with ethanol.

\section{Oligonucleotide primers}

Oligonucleotides used for primer extensions were synthesized in an Applied Biosystems 392 DNA Synthesizer, dried and eth- anol precipitated. The oligonucleotides were gel purified, desalted in a Sep-Pak column (Waters), dried, ethanol precipitated, and stored in solution at $-20^{\circ} \mathrm{C}$. The oligonucleotides are referred to by number; their sequence, position and orientation in the LTR sequence is summarized in Table 1.

\section{Primer extensions}

Oligonucleotide primers were phosphorylated with $100 \mu \mathrm{Ci}$ of $\left[\gamma^{-32} \mathrm{P}\right]$ ATP per pmole of primer, at $5000-6000 \mathrm{Ci} / \mathrm{mmole}$ using T4 kinase. The kinase was heat inactivated, and the labeled oligonucleotides were desalted by spin-column chromatography through Sephadex G-25. Each primer extension reaction used 0.4 pmoles of labeled oligonucleotide and $0.2-1 \mu \mathrm{g}$ of template DNA, in $50 \mathrm{mM} \mathrm{KCl}, 3.5 \mathrm{mM} \mathrm{MgCl}_{2}, 0.1 \%$ Triton X-100, $10 \mathrm{~mm}$ Tris-Cl (pH 8.3), $200 \mu \mathrm{M}$ dNTPs, and 2.5 units of Taq polymerase in a reaction volume of $30 \mu \mathrm{l}$. Primer extensions were cycled thermally to achieve a linear amplification of the signal. The melting temperatures were calculated with the OLIGO program (NBI, MN). Reaction products were extracted and ethanol precipitated in the presence of carrier RNA before electrophoresis in $8 \%$ sequencing gels. The amount of carrier RNA was kept to a minimum $(2.5 \mu \mathrm{g})$ as it contained material that interfered with the migration of primer extension products of an approximate size of 122 nucleotides. Visualization of the electrophoresed products was carried out with a PhosphorImager (Molecular Dynamics).

\section{Acknowledgments}

We thank S. Davis and Ron Wolford for expert technical assistance, and Barbour Warren, Han Htun, and Bill Pennie for critical discussions. We also thank R.C. Huang for critically reading the manuscript.

The publication costs of this article were defrayed in part by payment of page charges. This article must therefore be hereby marked "advertisement" in accordance with 18 USC section 1734 solely to indicate this fact.

\section{References}

Adom, J.N., F. Gouilleux, and H. Richard-Foy. 1992. Interaction with the nuclear matrix of a chimeric construct containing a replication origin and a transcription unit. Biochim. Biophys. Acta. 1171: 187-197. 
Almer, A., H. Rudolph, A. Hinnen, and W. Horz. 1986. Removal of positioned nucleosomes from the yeast PHO5 promoter upon PHO5 induction releases additional upstream activating DNA elements. EMBO I. 5: 2689-2696.

Archer, T.K., M.G. Cordingley, R.G. Wolford, and G.L. Hager. 1991. Transcription factor access is mediated by accurately positioned nucleosomes on the mouse mammary tumor virus promoter. Mol. Cell. Biol. 11: 6880-698.

Archer, T.K., P. Lefebvre, R.G. Wolford, and G.L. Hager. 1992. Transcription factor loading on the MMTV promoter: A bimodal mechanism for promoter activation. Science 255: 1573-1576.

Archer, T.K., H.-L. Lee, M.G. Cordingley, J.S. Mymryk, G. Fragoso, D.S. Berard, and G.L. Hager. 1994. Differential steroid hormone induction of transcription from the mouse mammary tumor virus promoter. Mol. Endocrinol. 8: 568-576.

Bresnick, E.H., S. John, and G.L. Hager. 1991. Histone hyperacetylation does not alter the position or stability of phased nucleosomes on the MMTV LTR. Biochemistry 30: 34903497.

Bresnick, E.H., M. Bustin, V. Marsaud, H. Richard-Foy, and G.L. Hager. 1992a. The transcriptionally-active MMTV promoter is depleted of histone H1. Nucleic Acids Res. 20: 273-278.

Bresnick, E.H., C. Rories, and G.L. Hager. 1992b. Evidence that nucleosomes on the mouse mammary tumor virus promoter adopt specific translational positions. Nucleic Acids Res. 20: $865-870$.

Buetti, E., B. Kühnel, and H. Diggelmann. 1989. Dual function of a nuclear factor I binding site in MMTV transcription regulation. Nucleic Acids Res. 17: 3065-3078.

Buttinelli, M., E. Di Mauro, and R. Negri. 1993. Multiple nucleosome positioning with unique rotational setting for the Saccharomyces cerevisiae $5 S$ rRNA gene in vitro and in vivo. Proc. Natl. Acad. Sci. 90: 9315-9319.

Clark, J.M. 1988. Novel non-templated nucleotide addition reactions catalyzed by procaryotic and eucaryotic DNA polymerases. Nucleic Acids. Res. 16: 9677-9686.

Cordingley, M.G., A.T. Riegel, and G.L. Hager. 1987. Steroiddependent interaction of transcription factors with the inducible promoter of mouse mammary tumor virus in vivo. Cell 48: 261-270.

Dingwall, C., G.P. Lomonossoff, and R.A. Laskey. 1981. High sequence specificity of micrococcal nuclease. Nucleic Acids Res. 9: 2659-2673.

Dong, F., J.C. Hansen, and K.E. van Holde. 1990. DNA and protein determinants of nucleosome positioning on sea urchin 5S gene sequences in vitro. Biochemistry 87: 57245728.

Drew, H.R. and C.R. Calladine. 1987. Sequence-specific positioning of core histones on an 860 base-pair DNA Experiment and theory. J. Mol. Biol. 195: 143-173.

Ewel, A., J.R. Jackson, and C. Benyajati. 1990. Alternative DNA-protein interactions in variable-length internucleosomal regions associated with Drosophila Adh distal promoter expression. Nucleic Acids Res. 18: 1771-1781.

Fedor, M.J., N.F. Lue, and R.D. Kornberg. 1988. Statistical positioning of nucleosomes by specific protein-binding to an upstream activating sequence in yeast. I. Mol. Biol. 204: 109-127.

Hansen, J.C., J. Ausio, V.H. Stanik, and K.E. van Holde. 1989. Homogeneous reconstituted oligonucleosomes, evidence for salt-dependent folding in the absence of histone H1. Biochemistry 28: 9129-9136.

Hartig, E. and A.C.B. Cato. 1994. In vivo binding of proteins to stably integrated MMTV DNA in murine cell lines: Occupancy of NF1 and OTFl binding sites in the absence and presence of glucocorticoids. Cell. Mol. Biol. Res. 40: 643652.

Hartig, E., B. Nierlich, S. Mink, G. Nebl, and A.C. Cato. 1993. Regulation of expression of mouse mammary tumor virus through sequences located in the hormone response element: Involvement of cell-cell contact and a negative regulatory factor. $J$. Virol. 67: 813-821.

Horz, W. and W. Altenburger. 1981. Sequence specific cleavage of DNA by micrococcal nuclease. Nucleic Acids Res. 9: 2643-2658.

Hynes, N., A.J. van Ooyen, N. Kennedy, P. Herrlich, H. Ponta, and B. Groner. 1983. Subfragments of the large terminal repeat cause glucocorticoid-responsive expression of mouse mammary tumor virus and of an adjacent gene. Proc. Natl. Acad. Sci. 80: 3637-3641.

Jackson, V. 1978. Studies on histone organization in the nucleosome using formaldehyde as a reversible cross-linking agent. Cell 15:945-954.

Jackson, V. and R. Chalkley. 1981. A new method for the isolation of replicative chromatin: Selective deposition of histone on both new and old DNA. Cell 23: 121-134.

Kalff, M., B. Gross, and M. Beato. 1990. Progesterone receptor stimulates transcription of mouse mammary tumour virus in a cell-free system. Nature 344: 360-362.

Ko, M.S., H. Nakauchi, and N. Takahashi. 1990. The dose dependence of glucocorticoid-inducible gene expression results from changes in the number of transcriptionally active templates. EMBO I. 9: 2835-2842.

Kornberg, R. 1981. The location of nucleosomes in chromatin: Specific or statistical [news]. Nature 292: 579-580.

Kornberg, R.D. and L. Stryer. 1988. Statistical distributions of nucleosomes: nonrandom locations by a stochastic mechanism. Nucleic Acids Res. 16: 6677-6690.

Lefebvre, P., D.S. Berard, M.G. Cordingley, and G.L. Hager. 1991. Two regions of the mouse mammary tumor virus LTR regulate the activity of its promoter in mammary cell lines. Mol. Cell. Biol. 11: 2529-2537.

Linxweiler, W. and W. Horz. 1984. Reconstitution of mononucleosomes: Characterization of distinct particles that differ in the position of the histone core. Nucleic Acids Res. 12: 9395-9413.

Majors, J. and H.E. Varmus. 1983. A small region of the mouse mammary tumor virus long terminal repeat confers glucocorticoid hormone regulation on a linked heterologous gene. Proc. Natl. Acad. Sci. 80: 5866-5870.

McGhee, J.D. and P.H. von Hippel. 1975. Formaldehyde as a probe of DNA structure. I. Reaction with exocyclic amino groups of DNA bases. Biochemistry 14: 1281-1296.

Meersseman, G., S. Pennings, and E.M. Bradbury. 1992. Mobile nucleosomes-A general behavior. EMBO J. 11: 2951-2959.

Mymryk, J.S., D. Berard, G.L. Hager, and T.K. Archer. 1995. MMTV chromatin in human breast cancer cells is constitutively hypersensitive and exhibits steroid hormone independent loading of transcription factors in vivo. Mol. Cell. Biol. 15: 26-34.

Noll, M. and R.D. Kornberg. 1977. Action of micrococcal nuclease on chromatin and the location of histone H1. I. Mol. Biol. 109: 393-404.

Pennie, W.D., G.L. Hager, and C.L. Smith. 1995. Nucleoprotein structure influences the response of the mouse mammary tumor virus promoter to activation of the cAMP signalling pathway. Mol. Cell. Biol. 15: 2125-2134.

Pennings, S., G. Meersseman, and E.M. Bradbury. 1991. Mobility of positioned nucleosomes on $5 \mathrm{~S}$ rDNA. $J$. Mol. Biol. 220: $101-110$.

Perlmann, T. and O. Wrange. 1988. Specific glucocorticoid re- 
ceptor binding to DNA reconstituted in a nucleosome. EMBO J. 7: 3073-3079.

Peterson, D.O. 1985. Alterations in chromatin structure associated with glucocorticoid-induced expression of endogenous mouse mammary tumor virus genes. Mol. Cell. Biol. 5: 1104-1110.

Pfeifer, G.P. and A.D. Riggs. 1991. Chromatin differences between active and inactive $\mathrm{X}$ chromosomes revealed by genomic footprinting of permeabilized cells using DNase $I$ and ligation-mediated PCR. Genes \& Dev. 5: 1102-1113.

Pina, B., D. Barettino, M. Truss, and M. Beato. 1990a. Structural features of a regulatory nucleosome. I. Mol. Biol. 216: 975990.

Pina, B., U. Brüggemeier, and M. Beato. 1990b. Nucleosome positioning modulates accessibility of regulatory proteins to the mouse mammary tumor vinus promoter. Cell 60: 719 731.

Richard-Foy, H. and G.L. Hager. 1987. Sequence specific positioning of nucleosomes over the steroid-inducible MMTV promoter. $E M B O /$. 6: 2321-2328.

Roberts, M.S., G. Fragoso, and G.L. Hager. 1995. The MMTV LTR B nucleosome adopts multiple translational and rotational positions during in vitro reconstitution. Biochemistry 34: (in press).

Roth, S.Y., A. Dean, and R.T. Simpson. 1990. Yeast $\alpha 2$ repressor positions nucleosomes in TRP1/ARS1 chromatin. Mol. Cell. Biol. 10: 2247-2260.

Satchwell, S.C., H.R. Drew, and A.A. Travers. 1986. Sequence periodicities in chicken nucleosome core DNA. I. Mol. Biol. 191: 659-675.

Shimizu, M., S.Y. Roth, C. Szen-Gyorgyi, and R.T. Simpson. 1991. Nucleosomes are positioned with base pair precision adjacent to the alpha2 operator in Saccharomyces cerevisiae. EMBO I. 10: 3033-3041.

Smith, C.L., T.K. Archer, G. Hamlin-Green, and G.L. Hager. 1993. Newly-expressed progesterone receptor cannot activate stable, replicated MMTV templates but acquires transactivation potential upon continuous expression. Proc. Natl. Acad. Sci. 90: 11202-11206.

Solomon, M.J. and A. Varshavsky. 1985. Formaldehyde-mediated DNA-protein crosslinking: A probe for in vivo chromatin structures. Proc. Natl. Acad. Sci. 82: 6470-6474.

Stallcup, M.R. and L.D. Washington. 1983. Region-specific initiation of mouse mammary tumor virus RNA synthesis by endogenous RNA polymerase II in preparations of cell nuclei. J. Biol. Chem. 258: 2802-2807.

Tack, L.C., P.M. Wassarman, and M.L. DePamphilis. 1981. Chromatin assembly. Relationship of chromatin structure to DNA sequence during simian virus 40 replication. I. Biol. Chem. 256: 8821-8828.

Thomas, G.H. and S.C. Elgin. 1988. Protein/DNA architecture of the DNase I hypersensitive region of the Drosophila hsp26 promoter [published erratum appears in EMBO I. 1988. 7(10): 3300]. EMBO I. 7: 2191-2201.

Toohey, M.G., J.W. Lee, M. Huang, and D.O. Peterson. 1990. Functional elements of the steroid hormone responsive promoter of mouse mammary tumor vinus. I. Virol. 64: 44774488.

Trifonov, E.N. and J.L. Sussman. 1980. The pitch of chromatin DNA is reflected in its nucleotide sequence. Proc. Natl. Acad. Sci. 77: 3816-3820.

Truss, M., G. Chalepakis, B. Pina, D. Barettino, U. Bruggemeier, M. Kalff, E.P. Slater, and M. Beato. 1992. Transcriptional control by steroid hormones. I. Steroid Biochem. Mol. Biol. 41: 241-248.

Truss, M., J. Bartsch, R.S. Hache, and M. Beato. 1993. Chroma- tin structure modulates transcription factor binding to the mouse mammary tumor virus (MMTV) promoter. J. Steroid Biochem. Mol. Biol. 47: 1-10.

Truss, M., J. Bartsch, and M. Beato. 1994. Antiprogestions prevent progesterone-receptor binding to hormone-responsive elements in-vivo. Proc. Natl. Acad. Sci. 91: 11333-11337.

Ucker, D.S., G.L. Firestone, and K.R. Yamamoto. 1983. Glucocorticoids and chromosomal position modulate murine mammary tumor virus transcription by affecting efficiency of promoter utilization. Mol. Cell. Biol. 3: 551-561.

Vanderbilt, J.N., R. Miesfeld, B.A. Maler, and K.R. Yamamoto. 1987. Intracellular receptor concentration limits glucocorticoid-dependent enhancer activity. Mol. Endocrinol. 1: 6874.

Venditti, P., G. Costanzo, R. Negri, and G. Camilloni. 1994. ABFI contributes to the chromatin organization of Saccharomyces cerevisiae ARS1 B-domain. Biochim. Biophys. Acta. 1219: 677-689.

Zaret, K.S. and K.R. Yamamoto. 1984. Reversible and persistent changes in chromatin structure accompany activation of a glucocorticoid-dependent enhancer element. Cell 38: 29-38.

Zinn, K. and T. Maniatis. 1986. Detection of factors that interact with the human beta-interferon regulatory region in vivo by DNAase I footprinting. Cell 45: 611-618. 


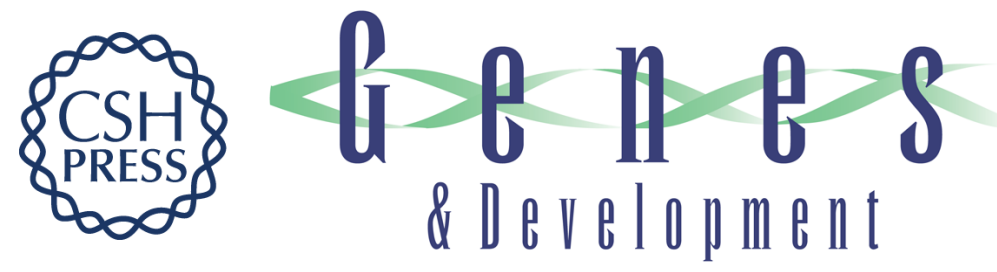

\section{Nucleosome positioning on the MMTV LTR results from the frequency-biased occupancy of multiple frames.}

G Fragoso, S John, M S Roberts, et al.

Genes Dev. 1995, 9:

Access the most recent version at doi:10.1101/gad.9.15.1933

References This article cites 60 articles, 19 of which can be accessed free at:

http://genesdev.cshlp.org/content/9/15/1933.full.html\#ref-list-1

License

Email Alerting

Service

Receive free email alerts when new articles cite this article - sign up in the box at the top right corner of the article or click here.

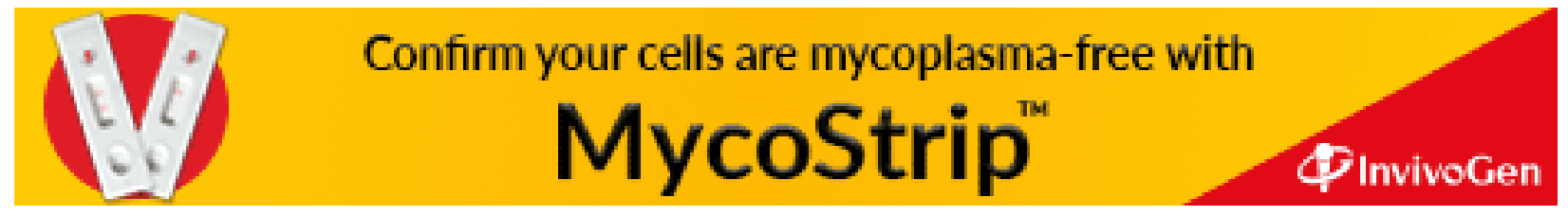

